\title{
The Reaction Mechanism of the Partial Oxidation of Methane to Synthesis Gas: A Transient Kinetic Study over Rhodium and a Comparison with Platinum
}

\author{
E. P. J. M allens, J. H . B. J. H oebink, and G. B. M arin \\ Schuit Institute of Catalysis, L aboratorium voor Chemische Technologie, E indhoven U niversity of Technology, P.O. B ox 513, \\ 5600 M B E indhoven, The N etherlands
}

Received D ecember 8, 1995; revised September 23, 1996; accepted N ovember 14, 1996

The partial oxidation of methane to synthesis gas over rhodium sponge has been investigated by admitting pulses of pure methane and pure oxygen as well as mixtures of methane and oxygen to rhodium sponge at temperatures from 873 to $1023 \mathrm{~K}$. Moreover, pulses of oxygen followed by methane and vice versa as well as pulses of mixtures of methane and labelled oxygen were applied to study the role of chemisorbed oxygen and incorporated oxygen in the reaction mechanism. The decomposition of methane on reduced rhodium results in the formation of carbon and hydrogen adatoms. D uring the interaction of pure dioxygen with rhodium the catalyst is almost completely oxidized to $\mathrm{Rh}_{2} \mathrm{O}_{3}$. In addition to rhodium oxide, oxygen is also present in the form of chemisorbed oxygen species. D uring the simultaneous interaction of methane and dioxygen at a stoichiometric feed ratio and a temperature of $973 \mathrm{~K}$ only $0.4 \mathrm{wt} \% \mathrm{Rh}_{2} \mathrm{O}_{3}$ is present. The chemisorbed oxygen species are completely desorbed after $2 \mathrm{~s}$. A Mars-Van Krevelen mechanism is postulated: methane reduces the rhodium oxide, which is reoxidized by dioxygen. Synthesis gas is produced as primary product. Hydrogen is formed via the associative desorption of two hydrogen adatoms from reduced rhodium and the reaction between carbon adatoms and oxygen present as rhodium oxide results in the formation of carbon monoxide. The consecutive oxidation of $\mathrm{CO}$ and $\mathrm{H}_{2}$ proceeds via both chemisorbed oxygen and oxygen present as rhodium oxide. Continuous flow experiments were performed to compare rhodium and platinum. When compared to platinum, rhodium shows a higher conversion to methane at a comparable temperature and also a higher selectivity to both $\mathrm{CO}$ and $\mathrm{H}_{2}$, the difference for $\mathrm{CO}$ being most pronounced. The observed differences in methane conversion and selectivities for the two catalysts are ascribed to the higher activation energy for methane decomposition on platinum compared to rhodium. An additional explanation for the difference in $\mathrm{H}_{2}$ selectivity could be the higher activation energy for $\mathrm{OH}$ formation on rhodium compared to platinum. $\odot 1997$ Academic Press

\section{INTRODUCTION}

Synthesis gas, a mixture of $\mathrm{CO}$ and $\mathrm{H}_{2}$, is used as feedstock for many important industrial processes, such as methanol production or the Fischer-Tropsch process.
Presently, the most important industrial route to synthesis gas is steam reforming of methane. A promising alternative for the production of synthesis gas is the partial oxidation of methane over supported transition metals due to the more favorable $\mathrm{H}_{2}$ to $\mathrm{CO}$ ratio in the product gas as well as the mild exothermicity of the reaction.

Prettre et al. (1) were among the first to report formation of synthesis gas by catalytic conversion of $\mathrm{CH}_{4} / \mathrm{O}_{2}$ mixtures at a stoichiometric feed ratio, i.e., a methane to oxygen feed molar ratio of 2 , over $10 \mathrm{wt} \%$ refractory supported $\mathrm{Ni}$ at temperaturesin the range of 973 to $1173 \mathrm{~K}$. Thermodynamic equilibrium was achieved under all conditions studied, corresponding to the catalyst bed exit temperature. The reaction was reported to occur in two stages. In the first stage methane is converted to $\mathrm{CO}_{2}$ and $\mathrm{H}_{2} \mathrm{O}$ until complete conversion of oxygen is achieved, since oxygen is the limiting reactant at a stoichiometric feed ratio. In the second stage synthesis gas is produced via secondary reactions such as the carbon dioxide and steam-reforming reaction.

A similar mechanism has been proposed for the partial oxidation of methane over $25 \mathrm{wt} \% \mathrm{Ni} / \mathrm{Al}_{2} \mathrm{O}_{3}$ (2), mixed metal oxides of $\mathrm{Ru}(3)$, various supported transition metals $(4,5)$, and various supported nickel catalysts $(6)$.

$B$ aerns and co-workers $(7,8)$ investigated the partial oxidation of methane over 1 wt $\% \mathrm{R} \mathrm{h} / \gamma-\mathrm{A} \mathrm{I}_{2} \mathrm{O}_{3}$ at a temperature of $1000 \mathrm{~K}$. A surface carbon species and $\mathrm{CO}_{2}$ are postulated to be the primary reaction products formed by the reaction of methane with reduced and oxidized surface sites. Formation of $\mathrm{CO}$ proceeds via a fast reaction between surface carbon species and $\mathrm{CO}_{2}$, i.e., the reversed B oudouard reaction. Furthermore, $\mathrm{OH}$ groups on the support are also considered to be involved in the $\mathrm{CH}_{x}$ conversion to $\mathrm{CO}$ via a reforming reaction.

Choudhary et al. (9-13) report selectivities to synthesis gas higher than the values predicted by thermodynamic equilibrium in the partial oxidation of methane over $\mathrm{NiO}-\mathrm{CaO}$ (9), 18.7 wt\% $\mathrm{Ni} / \mathrm{A} \mathrm{I}_{2} \mathrm{O}_{3}$ (10), $\mathrm{Ni} / \mathrm{Y} \mathrm{b}_{2} \mathrm{O}_{3}$ (11), $\mathrm{CoO} / \mathrm{rare}$ earth oxides (12), and $\mathrm{CoO} / \mathrm{M} \mathrm{gO}$ (13) at temperatures lower than $973 \mathrm{~K}$ and a residence time of $10^{-2} \mathrm{~s}$. The 
authors attribute this observation to primary formation of synthesis gas. However, D issanayake et al. (14) report that a difference between the measured and the actual reaction temperature also provides an explanation for the observed difference in selectivities.

Formation of $\mathrm{CO}$ and $\mathrm{H}_{2}$ as primary reaction products in the partial oxidation of methane is reported by $\mathrm{H}$ ickman and Schmidt (15-17) applying adiabatically operated monoliths containing a platinum or rhodium catalyst at outlet temperatures around $1300 \mathrm{~K}$ and residence times between $10^{-4}$ and $10^{-2} \mathrm{~s}$. Simulations carried out on the basis of a model consisting of 19 elementary reaction steps provided a theoretical basis for this observation (18).

Parallel formation of $\mathrm{CO}$ and $\mathrm{CO}_{2}$ during the partial oxidation of methane is reported by Lapszewicz and Jiang (19) for transition metal(s) supported on metal oxide(s) and Matsumura and Moffat (20) applying a $10 \mathrm{wt} \% \mathrm{Ru} / \mathrm{SiO}_{2}$ catalyst.

The interaction of dioxygen with rhodium and the formation of an oxide phase is of interest in the partial oxidation of methane. Formation of $\mathrm{R}_{2} \mathrm{O}_{3}$ is reported by various authors during the treatment of rhodium with dioxygen or air at various pressures and temperatures. Salanov and Savchenko (21-24) investigated the interaction of oxygen with $\mathrm{R} h(100)$ and polycrystalline rhodium. A toxygen pressures below $10^{-5} \mathrm{~Pa}$ and temperatures between 400 and $1600 \mathrm{~K}$ oxygen can occur in various states, depending on the surface coverage $(21,22)$, namely chemisorbed on the surface, penetrated into the near-surface layer of the metal and as part of surface oxide islands. A t oxygen pressures higher than $0.1 \mathrm{~Pa}$ up to $1000 \mathrm{~Pa}$ and temperatures between 400 and $600 \mathrm{~K}$ formation of a bulk $\mathrm{R}_{2} \mathrm{O}_{3}$ phase is reported $(23,24)$. Peuckert $(25)$ studied the oxidation of polycrystalline rhodium at $870 \mathrm{~K}$ and an oxygen pressure of $10^{5} \mathrm{~Pa}$. The surface was analyzed by means of $X$-ray photoelectron spectroscopy and it was concluded that a $\mathrm{R}_{2} \mathrm{O}_{3}$ phase was formed. Wang and Schmidt (26) investigated the surface composition of rhodium particles on planar amorphous $\mathrm{SiO}_{2}$ following treatment at atmospheric pressure and various temperatures in air or $\mathrm{H}_{2}$. A complete oxidation to $\mathrm{R}_{2} \mathrm{O}_{3}$ is reported as a result of a treatment with air at $773 \mathrm{~K}$. The oxidation kinetics of rhodium in air at $10^{5} \mathrm{~Pa}$ in the temperature range of 873 to $1273 \mathrm{~K}$ wasstudied by $\mathrm{C}$ arol and $\mathrm{M}$ ann (27) and formation and growth of $\mathrm{R}_{2} \mathrm{O}_{3}$ was reported. Two structures, a hexagonal and an orthorhombic crystal structure, control the nature of the oxidation kinetics. Beck et al. (28) studied changes in the local structure of rhodium oxide particles in a $\mathrm{Rh} / \mathrm{A} \mathrm{I}_{2} \mathrm{O}_{3}$ catalyst caused by treatment in dioxygen at atmospheric pressure and temperatures in the range of 800 to $1400 \mathrm{~K}$. A complete oxidation of rhodium to $\mathrm{R}_{2} \mathrm{O}_{3}$ was reported at temperatures at or above $800 \mathrm{~K}$ and the $\mathrm{R}_{2} \mathrm{O}_{3}$ particles have a structure similar to orthorhombic $\mathrm{R}_{2} \mathrm{O}_{3}$. K ellog $(29,30)$ reported formation of stoichiometric $\mathrm{R}_{2} \mathrm{O}_{3}$ on rhodium surfaces at temperatures of $500 \mathrm{~K}$ and higher at an oxygen pressure of $130 \mathrm{~Pa}$.

The reduction characteristics of $\mathrm{R}_{2} \mathrm{O}_{3}$ are also of interest. A ccording to Peuckert (25) the decomposition of the $\mathrm{Rh}_{2} \mathrm{O}_{3}$ phase proceeds via a mixed phase of metallic rhodium and $\mathrm{Rh}_{2} \mathrm{O}_{3}$. Treatment of $\mathrm{R}_{2} \mathrm{O}_{3}$ particles in hydrogen at $423 \mathrm{~K}$ results in complete reduction to rhodium metal, as reported by Wang and Schmidt (26). $\mathrm{R}_{2} \mathrm{O}_{3}$ was also reduced by $\mathrm{CO}$ at a pressure of $133 \mathrm{~Pa}$ at temperatures above $420 \mathrm{~K}$, as reported by K ellog (30). O h and Carpenter (31) investigated the oxidation state of rhodium following pretreatment with several gases between 500 and $800 \mathrm{~K}$. The oxidation state of supported rhodium changed reversibly in response to a change in the stoichiometry of its gaseous environment. The catalyst surface was observed to consist mainly of $\mathrm{R}_{2} \mathrm{O}_{3}$ in a net-oxidizing environment, while in the case of a net-reducing stream mainly metallic rhodium is present.

The objective of the present study is to investigate the reaction mechanism of the partial oxidation of methane to synthesis gas over rhodium by means of a transient kinetic study. A Temporal A nalysis of Products (TA P) set-up was applied, which allows one to introduce pulses of gases into a reactor. The amount of molecules can be varied between $10^{14}$ and $10^{18}$ per pulse and the width of the inlet pulse typically amounts to $0.2 \mathrm{~ms}$. Thermodynamic calculations on the system oxygen-rhodium were performed to assess the possible formation of an oxide phase under the experimental conditions, from a thermodynamic point of view. B oth the separate and the simultaneous interaction of methane and dioxygen with the catalyst as well as the reactivity of different oxygen species in the partial oxidation of methane were studied. The emphasis was put on obtaining information concerning these phenomena on a catalyst which was at steady state with an environment as typical as possible for the partial oxidation, i.e., a temperature of $1100 \mathrm{~K}$ and a gas phase consisting of methane and oxygen in a feed molar ratio of 2. The reaction paths are analyzed in terms of primary and secondary product formation and a detailed reaction mechanism is proposed. K nudsen diffusion, combined with adsorption and desorption processes are simulated by integrating the continuity equations for the reaction products in order to avoid interference of the latter with the reaction network analysis. The results are compared to previous work involving platinum as the catalyst (32).

\section{EXPE RIMENTAL}

\section{E quipment and $P$ rocedures}

The TA P set-up has been described in detail elsewhere (33). The microreactor of the TA P set-up is a batchwise operated fixed bed reactor with a typical residence time of $100 \mathrm{~ms}$. M ass spectrometry is used to follow the outlet 
reponses toward pulses of reactants admitted at the inlet with a submillisecond time resolution. It allows one to study catalytic sequences in detail, even at a high conversion. $A$ limited amount of molecules is admitted to the catalyst surface leading to information about the reactants and products at a well defined state of the surface.

The shape of a response is determined by the various processes occurring in the microreactor, namely $\mathrm{K}$ nudsen diffusion, adsorption, desorption, and reaction. Each response has a unique rise time, peak maximum, and decay curve.

A plot of the responses as a function of time contains in principle information on the reaction network. A secondary product has a response with a larger rise time than a primary product and its peak maximum is observed later. A dsorption and desorption processes result in a shift of the peak maximum toward a larger time value. The position of the peak maximum is also determined by the molecular weight of the component via the $\mathrm{K}$ nudsen diffusion coefficient.

The continuous flow mode of operation of the microreactor was applied for the pretreatment of the catalyst and determination of the absolute calibration factors. The latter allows one to convert the mass spectrometer signal into moles per second. The total flow in a continuous flow experiment amounts to $210^{-7} \mathrm{~mol} \mathrm{~s}^{-1}$, resulting in an average pressure in the microreactor in the order of $10^{4} \mathrm{~Pa}$.

Transient experiments were performed in three different ways. The first type is referred to as a pulse experiment, during which the response to a single pulse is monitored at a fixed atomic mass unit ( $A M U)$ value.

The second type is referred to as an alternating pulse experiment, also called pump-probe experiment (33). Two single pulses are introduced and the response is measured at a fixed $A M U$ value. By varying the time interval between the two single pulses information on the lifetime and reactivity of adsorbed species is obtained. These species are created during the first single pulse and probed with a suitable reactant during the second single pulse.

In both a pulse and an alternating pulse experiment pulses are repeated regularly and the responses are averaged to improve the signal-to-noise ratio. The repetition time is chosen sufficiently large to avoid accumulation of adsorbed species at the surface. This sequence is repeated for each A M U value to be measured.

The third type concerns a multipulse experiment. A series of single pulses is introduced and the responses of all pulses are monitored separately, i.e., without signal averaging, at a fixed A M U value. The time interval between two single pulses is variable and must be larger than the average residence time in the reactor to avoid accumulation of components in the void space of the catalyst bed. A multipulse experiment can be used to study the interacion of a component with the surface at different degrees of surface coverage.
The number of molecules admitted per single pulse was in the range of $10^{15}-10^{16}$, resulting in an average total pressure of $100 \mathrm{~Pa}$ above the catalyst surface during $100 \mathrm{~ms}$. G as phase reactions can be neglected under these conditions. In a single pulse the ratio of admitted methane as well as oxygen molecules to the theoretical number of surface rhodium atoms was always below 0.05 . The background pressure in the reactor section of the set-up amounts to $10^{-5} \mathrm{~Pa}$.

The inconel microreactor, with a length of $42 \mathrm{~mm}$ and an inner diameter of $6 \mathrm{~mm}$, was charged with 0.07 to $0.2 \mathrm{~g}$ of catalyst and packed with inert material at each end. Two thermocouples were inserted into the catalyst bed for temperature measurements. The axial temperature difference over the bed was al ways limited to $5 \mathrm{~K}$.

The experiments were carried out in the temperature range of 873 to $1023 \mathrm{~K}$. The detected reaction products were $\mathrm{H}_{2}, \mathrm{CO}, \mathrm{H}_{2} \mathrm{O}$, and $\mathrm{CO}_{2}$. No formation of $\mathrm{C}_{2}$-products was observed. For each experiment the conversion and selectivities as well as carbon, hydrogen, and oxygen balances were calculated, according to the following equations.

$$
\begin{aligned}
& X_{\mathrm{CH}_{4}}=\frac{n_{\mathrm{in}, \mathrm{CH}_{4}}-n_{\mathrm{out}, \mathrm{CH}_{4}}}{n_{\mathrm{in}, \mathrm{CH}_{4}}} \\
& S_{\mathrm{H}_{2}}=\frac{n_{\text {out }, \mathrm{H}_{2}}}{n_{\text {out }, \mathrm{H}_{2}}+n_{\text {out }, \mathrm{H}_{2} \mathrm{O}}}
\end{aligned}
$$

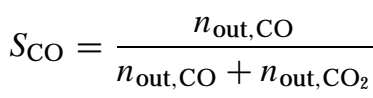

$$
\begin{aligned}
& \epsilon_{\mathrm{C}}=\frac{n_{\text {out, } \mathrm{CH}_{4}}+n_{\text {out, } \mathrm{CO}}+n_{\text {out }, \mathrm{CO}_{2}}-n_{\text {in, } \mathrm{CH}_{4}}}{n_{\text {in, } \mathrm{CH}_{4}}} \\
& \epsilon_{\mathrm{O}}=\frac{2 n_{\text {out }, \mathrm{O}_{2}}+n_{\text {out }, \mathrm{CO}}+2 n_{\text {out }, \mathrm{CO}_{2}}+n_{\text {out }, \mathrm{H}_{2} \mathrm{O}}-2 n_{\text {in }, \mathrm{O}_{2}}}{2 n_{\mathrm{in}, \mathrm{O}_{2}}} \\
& \epsilon_{\mathrm{H}}=\frac{4 n_{\text {out, } \mathrm{CH}_{4}}+2 n_{\text {out, } \mathrm{H}_{2}}+2 n_{\text {out, } \mathrm{H}_{2} \mathrm{O}}-4 n_{\text {in, } \mathrm{CH}_{4}}}{4 n_{\text {in, } \mathrm{CH}_{4}}},
\end{aligned}
$$

where $X$ is the conversion ( $\mathrm{mol} \mathrm{mol}^{-1}$ ), $\mathrm{S}$ is the selectivity ( $\mathrm{mol} \mathrm{mol}^{-1}$ ), $\mathrm{n}$ is the total amount of moles (mol), and $\epsilon$ is the mass balance $\left(\mathrm{mol} \mathrm{mol}^{-1}\right)$.

The carbon, hydrogen, and oxygen balances always showed an accuracy better than $8 \%$. E rrors up to $15 \%$ are considered to be acceptable in view of the accuracy of the absolute calibration factor. The conversion of methane was always nearly complete, unless specified otherwise.

A pparent activation energies for the interaction of oxygen and methane with the catalyst were derived from the linear dependence of $\ln X$ on the inverse temperature, applying an identical amount of molecules per pulse at various temperatures. 0 nly experiments in which the conversion is lower than $50 \%$ were selected for determination of the activation energies. 


\section{M aterials}

The gases used were methane $(99.9995 \%)$, oxygen $(99.995 \%)$, carbon monoxide $(99.9997 \%)$, carbon dioxide $(99.995 \%)$, hydrogen $(99.999 \%)$, and argon (99.99995\%) from $A$ ir Products. Labelled oxygen, ${ }^{18} \mathrm{O}_{2}$ (99.5\%) from U nion Carbide was used as well.

The catalysts applied were rhodium sponge (99.9\%) and platinum sponge ( $99.9 \%$ ), both from J ohnson M atthey, with a grain diameter of 0.25 to $0.35 \mathrm{~mm}$. The BE T surface area of the fresh rhodium catalyst amounted to $0.25 \mathrm{~m}^{2} \mathrm{~g}^{-1}$ and for the fresh platinum catalyst to $0.05 \mathrm{~m}^{2} \mathrm{~g}^{-1}$. These surface areas correspond to diameters of the primary nonporous particles forming the porous grain of $5 \mu \mathrm{m}$ for platinum and $2 \mu \mathrm{m}$ for rhodium. Nonporous $\alpha-\mathrm{A} \mathrm{I}_{2} \mathrm{O}_{3}$ with a grain diameter of 0.25 to $0.30 \mathrm{~mm}$ was used as inert packing material. The catalyst has two important advantages for the present study. No support is used to avoid interactions between the metal and a support material as well as interactions between reactants or reaction products and a support material. Second, the time scale for K nudsen diffusion in the interstitial voids is 100 times the time scale of K nudsen diffusion in the intragranular voids. This means that the shape of the response is not influenced by intragranular diffusion (34).

$\mathrm{B}$ lank pulse experiments of methane as well as methane with oxygen over $\alpha-\mathrm{Al}_{2} \mathrm{O}_{3}$ showed a conversion of $2 \%$, which is negligible compared to conversions obtained in the presence of a catalyst. In all experiments argon was added to the admitted gases as a reference component for calculation of the conversion of the reactants and the amount of admitted molecules.

The amount of surface metal atoms and of metal oxide was determined in situ. The former followed from a multipulse experiment of oxygen at a temperature of $373 \mathrm{~K}$ over a surface covered with carbon monoxide. The responses of carbon dioxide were monitored and their cumulative surface area provided the amount of carbon dioxide molecules formed which is considered identical to the number of surface metal atoms. The specific surface area based on a theoretical amount of $1.32 \times 10^{19}$ rhodium atoms per square meter and of $1.30 \times 10^{19}$ platinum atoms per square meter, was found to be identical to that determined ex situ by the BET method. The amount of metal oxide was determined by both a continuous flow and a multipulse experiment of hydrogen. The response of water was measured from which the amount of incorporated oxygen was deduced. In the case of a multipulse experiment typical 200 pulses of hydrogen are introduced, during which the number of molecules per pulse is in the range of $10^{16}-10^{17}$. For a continuous flow experiment a flow of $10^{-7}-10^{-6} \mathrm{~mol} \mathrm{~s}^{-1}$ is applied. I $\mathrm{n}$ both cases the experiment is continued until the water production is negligible. Integration of the water response yields the total amount of atomic oxygen present as metal oxide. $R$ epetition of a multipulse reduction at various time intervals after the experiment did not show water formation, from which it is concluded that complete reduction has occurred.

The catalyst was pretreated in situ for $2 \mathrm{~h}$ at a temperature of $1123 \mathrm{~K}$ with a continuous flow of a mixture of $80 \mathrm{vol} \%$ oxygen in argon, followed by a flow of 80 vol\% hydrogen in argon. A fter the pretreatment the specific surface area had decreased to $0.23 \mathrm{~m}^{2} \mathrm{~g}^{-1}$ for rhodium and to $0.035 \mathrm{~m}^{2} \mathrm{~g}^{-1}$ for platinum. These values remained constant during the various subsequent experiments.

Prior to each transient experiment, as defined above, the catalyst was treated with a continuous flow of methane and oxygen, unless mentioned otherwise, in the same feed molar ratio as the following experiment, after which it was kept under a pressure of $10^{-5} \mathrm{~Pa}$ for $5 \mathrm{~min}$.

\section{MODEL EQUATIONS FOR THE SIMULATION OF ADSORPTION, DESORPTION, AND KNUDSEN DIFFUSION PROCESSES}

The outlet flow rates of the four reaction products were calculated by integrating the corresponding continuity equations for a single pulse of an equimolar mixture of $\mathrm{CO}$, $\mathrm{CO}_{2}, \mathrm{H}_{2}$, and $\mathrm{H}_{2} \mathrm{O}$ and corresponding $\mathrm{K}$ nudsen diffusion, adsorption, and desorption coefficients to investigate the influence of these processes on the shape of the responses. Reaction is not included in the simulations. Comparison of these simulation results with the results obtained by simultaneous pulsing of methane and oxygen allows one to ascertain that the above phenomena do not disguise the reaction network analysis of the partial oxidation of methane to synthesis gas.

In general when studying a catalytic reaction with the TA P set-up, the microreactor will be packed with three subsequent beds. The response after injection of a gas pulse is a function of all processes appearing in the reactor, gas transport, adsorption, desorption, and reaction, and can be simulated by integrating the continuity equations for all components considered. When the catalyst bed is placed in the isothermal part of the reactor, the energy balances can be omitted. In the present analysis, the only processes taken into consideration are diffusion, adsorption, and desorption.

It is assumed that the only transport mechanism of molecules through the reactor is K nudsen diffusion. This assumption is valid since the amount of molecules per pulse was always below $10^{16}$ and under these conditions $\mathrm{K}$ nudsen diffusion is the dominant transport mechanism (34). The effective $K$ nudsen diffusion coefficient of component $A$, is calculated as

$$
D_{\mathrm{e}, \mathrm{A}}^{\kappa}=\frac{\varepsilon_{\mathrm{b}}}{\tau_{\mathrm{b}}} \frac{d_{\mathrm{i}}}{3} \sqrt{\frac{8 R T}{\pi M_{\mathrm{A}}}},
$$

where $D_{\mathrm{e}, \mathrm{a}}^{\kappa}$ is the effective $\mathrm{K}$ nudsen diffusion coefficient $\left(\mathrm{m}_{\mathrm{g}}^{3} \mathrm{~m}_{\mathrm{r}}^{-1} \mathrm{~s}^{-1}\right), \varepsilon_{\mathrm{b}}$ is the bed porosity $\left(0.6 \mathrm{~m}_{\mathrm{g}}^{3} \mathrm{~m}_{\mathrm{r}}^{-3}\right), \tau_{\mathrm{b}}$ is the bed tortuosity $\left(5.6 \mathrm{~m}_{\mathrm{g}}^{2} \mathrm{~m}_{\mathrm{r}}^{-2}\right), d_{\mathrm{i}}$ is the diameter of the 
interstitial voids $(\mathrm{m}), \mathrm{R}$ is the general gas constant $\left(\mathrm{J} \mathrm{mol} \mathrm{l}^{-1}\right.$ $\left.\mathrm{K}^{-1}\right), \mathrm{T}$ is the temperature ( $\left.\mathrm{K}\right)$, and $\mathrm{M}_{\mathrm{A}}$ is the molecular mass $\left(\mathrm{kg} \mathrm{mol}^{-1}\right)$.

The diameter of the intersitial voids, $d_{i}$, follows from the definition for the hydraulic diameter (35). The continuity equations are shown for a general case of component $A$, showing first order adsorption and desorption:

$$
A+* \underset{k_{\text {des }}}{\stackrel{k_{\mathrm{ads}}}{\rightleftarrows}} A *,
$$

where $*$ signifies an adsorption site. The gas phase concentration profile of component $A$ as function of the reactor coordinate can be calculated by integrating the continuity equations for component $A$ in each of the packed beds, i.e., two inert beds and one catalyst bed. O nly the balances for the catalyst bed are presented here. In the case of the inert beds the reaction terms in the continuity equations can be put equal to zero.

The continuity equations for the gas phase component $A$ and the corresponding adsorbed species over the catalyst bed as well as the initial and boundary conditions are

$$
\begin{aligned}
\varepsilon_{\mathrm{b}} \frac{\partial C_{\mathrm{A}}}{\partial t}= & D_{\mathrm{e}, \mathrm{A}}^{\kappa} \frac{\partial^{2} C_{\mathrm{A}}}{\partial x^{2}} \\
& +\left(1-\varepsilon_{\mathrm{b}}\right) a_{\mathrm{v}} L_{\mathrm{t}}\left(-k_{\mathrm{ads}} C_{\mathrm{A}}\left(1-\theta_{\mathrm{A}}\right)+k_{\mathrm{des}} \theta_{\mathrm{A}}\right) \\
\frac{\partial \theta_{\mathrm{A}}}{\partial t}= & k_{\mathrm{ads}} C_{\mathrm{A}}\left(1-\theta_{\mathrm{A}}\right)-k_{\mathrm{des}} \theta_{\mathrm{A}} .
\end{aligned}
$$

The initial conditions follow from the initial gas phase concentration and the initial surface coverage of component $A$ :

$$
\begin{aligned}
& t=0 \wedge 0 \leq x \leq l_{\mathrm{b}}: C_{\mathrm{A}}(x)=\delta_{x} \frac{N_{\mathrm{p}, \mathrm{A}}}{\varepsilon_{\mathrm{b}} A_{\mathrm{s}}} \\
& t=0 \wedge 0 \leq x \leq l_{\mathrm{b}}: \theta_{\mathrm{A}}(x)=0 .
\end{aligned}
$$

The two boundary conditions are shown below. A fter the introduction of the gas pulse, the pulse valve is closed meaning a zero flux at the reactor entrance:

$$
t \geq 0 \wedge x=0: \frac{\partial C_{\mathrm{A}}}{\partial x}=0 .
$$

The concentration for component $A$ at the end of the catalyst bed can be put equal to zero, because the reactor outlet is maintained at a pressure of $10^{-5} \mathrm{~Pa}$ :

$$
t \geq 0 \wedge x=l_{\mathrm{b}}: C_{\mathrm{A}}=0,
$$

where $a_{v}$, is the external catalyst surface area per unit catalyst volume $\left(8.910^{5} \mathrm{~m}_{\mathrm{c}}^{2} \mathrm{~m}_{\mathrm{c}}^{-3}\right), L_{\mathrm{t}}$ is the maximal molar concentration per square meter of catalyst surface $\left(2.210^{5}\right.$ mol $\left.\mathrm{m}_{\mathrm{c}}^{-2}\right), \theta$ is the fractional coverage on the surface $(-), k_{a d s}$ is the adsorption rate coefficient, and $k_{\text {des }}$ is the desorption rate coefficient.
The partial differential equations with the accompanying initial and boundary conditions were integrated numerically with the routine D03PGF from the NAG Fortran L ibrary, as described by Huinink (34). The K nudsen diffusion coefficients were calculated using the relationship given by Eq. [7], for a particle diameter of $300 \mu \mathrm{m}$. The values for the adsorption and desorption rate coefficients are obtained from $\mathrm{H}$ ickman and Schmidt (15), since these values are taken from studies on unsupported single crystals as well as polycrystalline catalyst studies. The adsorption and desorption of $\mathrm{CO}_{2}$ are neglected in their model.

The results of the simulations are shown in Fig. 1, which shows the normalized responses of hydrogen, water, carbon monoxide, and carbon dioxide when $\mathrm{K}$ nudsen diffusion, adsorption, and desorption are considered. In this case the response of water is observed prior to that of hydrogen and the response of carbon dioxide is observed prior to that of carbon monoxide.

The shape of the responses can be explained qualitatively by comparison of the characteristic times of $\mathrm{K}$ nudsen diffusion, adsorption, and desorption for hydrogen, water, and carbon monoxide. These values are calculated by

$$
\begin{aligned}
\tau_{\text {diff }} & =\frac{l_{\mathrm{b}}^{2} \varepsilon_{\mathrm{b}}}{2 D_{\mathrm{e}, \mathrm{A}}^{\kappa}} \\
\tau_{\mathrm{ads}} & =\frac{\varepsilon_{\mathrm{b}}}{\left(1-\varepsilon_{\mathrm{b}}\right) a_{\mathrm{v}} L_{\mathrm{t}} k_{\mathrm{ads}} \theta_{*}} \\
\tau_{\mathrm{des}} & =\frac{1}{k_{\mathrm{des}}},
\end{aligned}
$$

where $\tau_{\text {diff, }} \tau_{\text {ads, }}$ and $\tau_{\text {des }}$ are the characteristic times for Knudsen diffusion, adsorption, and desorption, respectively.

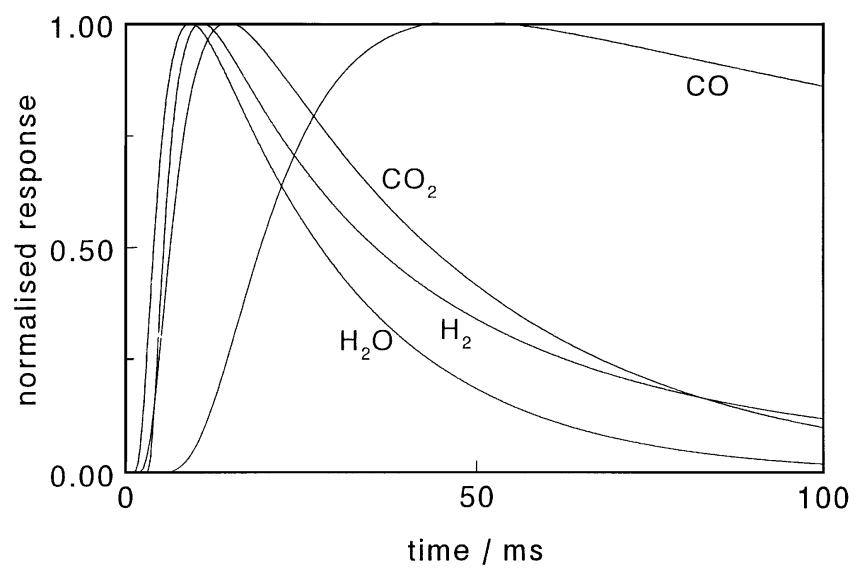

FIG . 1. N ormalized responses of $\mathrm{H}_{2}(\times 1.72), \mathrm{H}_{2} \mathrm{O}, \mathrm{CO}(\times 10.14)$, and $\mathrm{CO}_{2}(\times 1.59)$ as a function of time. Simulation of $\mathrm{K}$ nudsen diffusion, adsorption, and desorption over rhodium sponge by integrating continuity E qs. [9] and [10] with initial and boundary conditions [11-14]. 
TABLE 1

\section{Characteristic Times for Knudsen Diffusion, Adsorption, and Desorption of Various $\mathbf{G}$ ases on $R$ hodium Sponge at a Temperature of $973 \mathrm{~K}$}

\begin{tabular}{lccc}
\hline \multirow{2}{*}{\multicolumn{1}{c}{ Process }} & \multicolumn{3}{c}{ Characteristic time (s) } \\
\cline { 2 - 4 } & $\mathrm{H}_{2}$ & $\mathrm{H}_{2} \mathrm{O}$ & $\mathrm{CO}$ \\
\hline K nudsen diffusion & $1.4 \times 10^{-2}$ & $2.3 \times 10^{-2}$ & $2.9 \times 10^{-2}$ \\
A dsorption & $5.6 \times 10^{-9}$ & $1.7 \times 10^{-8}$ & $6.5 \times 10^{-9}$ \\
D esorption & $2.2 \times 10^{-9}$ & $2.7 \times 10^{-11}$ & $3.1 \times 10^{-7}$ \\
\hline
\end{tabular}

The results are shown in Table 1 for a total bed length of $25 \times 10^{-3} \mathrm{~mm}$ and a temperature of $973 \mathrm{~K}$. In the case of hydrogen an adsorption equilibrium can be expected which explains the broadening of the hydrogen response due to adsorption and desorption phenomena. For carbon monoxide the relatively slow desorption from the surface causes the large broadening of the response. In the case of water the response resembles that determined by diffusion alone, becuase the equilibrium is on the side of gaseous water.

\section{THERMODYNAMIC EVALUATION OF THE SYSTEM OXYGEN-RHODIUM}

In order to obtain insight into the thermodynamic stability of the possible species in the system oxygen-rhodium, thermodynamic calculations were performed at $1000 \mathrm{~K}$.

The species to be considered in the thermodynamic equilibrium calculations are $\mathrm{O}_{2(\mathrm{~g})}, \mathrm{R} \mathrm{h}_{(\mathrm{c})}, \mathrm{R}_{(\mathrm{g})}, \mathrm{R} \mathrm{h}_{2} \mathrm{O}_{(\mathrm{c})}, \mathrm{R} \mathrm{hO}(\mathrm{c})$, $\mathrm{Rh}_{2} \mathrm{O}_{3(\mathrm{c})}$, and $\mathrm{RhO}_{2(\mathrm{~g})}$, according to Schäfer et al. (36), A lcock and Hooper (37) and Barin (38). A convenient representation of systems involving three gaseous species is possible in a so-called volatility diagram. Volatility diagrams show the activities of two gaseous species in equilibrium with the condensed phases at a given temperature. The construction and use of this type of diagram is discussed by H euer (39) and Lou et al. (40) Thermodynamic data from $B$ arin (38), B arin and K nacke (41), and A Icock and H ooper (37) are used in the calculations.

The following basic assumptionswere used in the thermodynamic calculations: (i) the condensed phases are pure and stoichiometric and (ii) the partial molar volume of gas phase components is much larger than that for solid phase components. A s a result of these two assumptions the chemical potential of a condensed component is equal to its standard chemical potential, which is only a function of the temperature. Furthermore, a constant pressure is assumed in the calculations.

The volatility diagram for the system oxygen-rhodium at a temperature of $1000 \mathrm{~K}$ is shown in Fig. 2. The volatility diagram consists of four fields, assigned to $\mathrm{R} h_{(c)}, \mathrm{R} \mathrm{h}_{2} \mathrm{O}_{(\mathrm{c})}$, $\mathrm{Rh}_{2} \mathrm{O}_{3(\mathrm{c})}$ and a gas phase, consisting of $\mathrm{RhO} \mathrm{O}_{2(\mathrm{~g})}, \mathrm{Rh}(\mathrm{g})$,

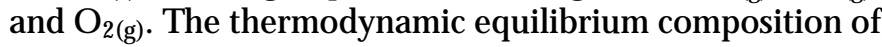
the gas phase is ruled by the equilibrium constant of the

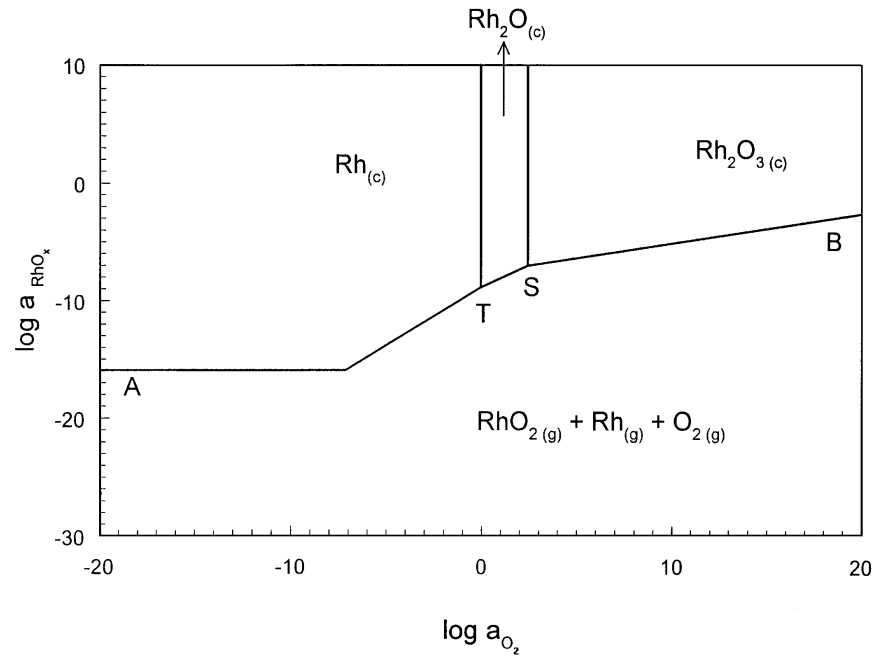

FIG. 2. Volatility diagram of oxygen/rhodium at a temperature of $1000 \mathrm{~K}$ and a constant pressure.

reaction

$$
\mathrm{RhO}_{2(\mathrm{~g})} \rightleftarrows \mathrm{Rh}_{(\mathrm{g})}+\mathrm{O}_{2(\mathrm{~g})} .
$$

A t given activity of $\mathrm{O}_{2(\mathrm{~g})}$ and $\mathrm{Rh}_{(\mathrm{g})}$, the activity of $\mathrm{R} \mathrm{hO} 2(\mathrm{~g})$ is fixed by the equilibrium of $E q$. [18]. The line $A$ to $B$ corresponds to an equilibrium between the gas phase and one or more condensed phases.

The triple points T and S (see Fig. 2) represent the points where three phases are in equlibrium. For example, at triple point $\mathrm{T}$ the condensed phases $\mathrm{R} \mathrm{h}_{\text {(c) }}$ and $\mathrm{R} \mathrm{h}_{2} \mathrm{O}$ (c) and the gas phase are in equilibrium, leaving the temperature as the only degree of freedom.

The minimum activity of oxygen necessary for the formation of $\mathrm{R}_{2} \mathrm{O}_{3}$ corresponds to the triple point $\mathrm{S}$ and amounts to $250 \mathrm{~Pa}$. D uring the experimental work with the TA P setup the average pressure of oxygen has a similar order of magnitude and therefore formation of $\mathrm{R}_{2} \mathrm{O}_{3 \text { (c) }}$ can be expected from a thermodynamic point of view during the interaction of oxygen with rhodium sponge at temperatures of approximately $1000 \mathrm{~K}$. The field corresponding to $\mathrm{R}_{2} \mathrm{O}_{3}$ as condensed phase becomes smaller with increasing temperature.

\section{EXPERIMENTAL RESULTS}

Interaction of Oxygen with R educed Rhodium

The interaction of oxygen with the catalytic surface was investigated with a continuousflow experiment of oxygen as well as multipulse experiments of oxygen. The catalyst was exposed to a continuous flow of oxygen at a temperature of $1073 \mathrm{~K}$. I n this case the catalyst was completely reduced prior to the experiment. I nitially oxygen was not detected quantitatively, but the oxygen response increased and finally reached a constant value after a period of $2500 \mathrm{~s}$. The argon response remained constant during this experiment. 
The gradual increase in the oxygen response is attributed to the incorporation of oxygen into the catalyst and the ratio of incorporated atomic oxygen to the number of rhodium atoms can be calculated to be 1.7 from the oxygen balance.

A sample of the treated catalyst as well as the fresh rhodium sponge was analyzed ex-situ by means of $X$-ray diffractometry (XRD) measurements as well as X-ray photoelectron spectroscopy (XPS) measurements. The fresh sample was reduced in situ at $973 \mathrm{~K}$ by hydrogen for $1 \mathrm{~h}$. A fter this reduction the sample was cooled to room temperature maintaining a pressure of $10^{-5} \mathrm{~Pa}$. Finally, the sample was transferred to the set-up for analysis. The former analysis showed that the treated sample consisted of stoichiometric $\mathrm{R}_{2} \mathrm{O}_{3}$ as well as metallic rhodium, while the fresh sample consisted solely of metallic rhodium. From the XPS measurements it was concluded that in the case of the treated sample stoichiometric $\mathrm{R}_{2} \mathrm{O}_{3}$ is present and that the ratio of oxidic atomic oxygen to rhodium atoms amounted to 1.7, which is identical to the value obtained from the continuous flow experiments. For the fresh sample solely metallic rhodium was detected. D uring the continuous flow of oxygen the average pressure of oxygen in the catalyst bed amounts to $10^{4} \mathrm{~Pa}$. Thermodynamic calculations (Fig. 2) show that at oxygen pressures of $250 \mathrm{~Pa}$ or higher a $\mathrm{R}_{2} \mathrm{O}_{3}$ phase is thermodynamically stable at the investigated temperature. Therefore, the incorporation of oxygen into the catalyst is attributed to the almost complete oxidation of rhodium to $\mathrm{R}_{2} \mathrm{O}_{3}$. A possible explanation for the absence of any surface oxygen in the case of the fresh sample is the structure of the catalyst, consisting of nonporous particles forming the porous grain of $2 \mu \mathrm{m}$, instead of a supported rhodium catalyst. This may also explain the partial decomposition of the treated sample, since XRD analysis revealed the presence of both $\mathrm{R}_{2} \mathrm{O}_{3}$ and metallic rhodium. This decomposition does not influence the XPS measurements under the assumptium that due to the diffusion of oxygen to the surface the latter remains oxidised.

The treated catalyst sample was kept for a time interval varying between zero and $1800 \mathrm{~s}$ at a pressure of $10^{-5} \mathrm{~Pa}$ and a temperature of $898 \mathrm{~K}$, after which multipulse experiments of oxygen were carried out. In a typical experiment 15 pulses were introduced with a 2-s time interval between the pulses. A typical result is shown in Fig. 3. The surface area of the individual oxygen responses increases and finally remains constant. The initial increase is attributed to oxygen incorporation into the catalyst. The amount of incorporated oxygen increases linearly with increasing time at $10^{-5} \mathrm{~Pa}$ up to 0.7 theoretical monolayers of atomic oxygen at $1800 \mathrm{~s}$. No constant value is reached as in the case of platinum after maintaining $10^{-5} \mathrm{~Pa}$ during at least $300 \mathrm{~s}$ (32). A second series of multipulse experiments was carried out at $900 \mathrm{~s}$ after interrupting the continuous flow of oxygen but now at temperatures between 875 and $948 \mathrm{~K}$. The amount of incorporated oxygen increases exponentially, expecially

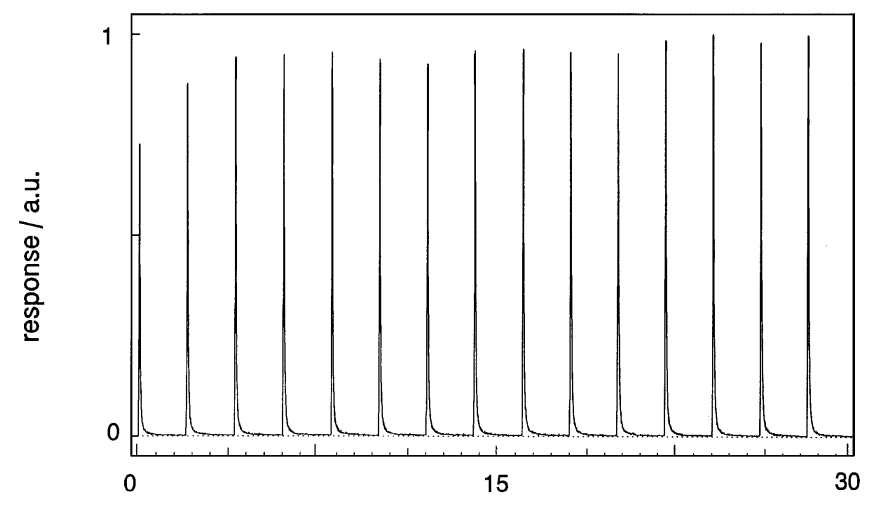

time / s

FIG . 3. R esponse of oxygen as a function of time. M ultipulse experiment of oxygen at $873 \mathrm{~K}$ over almost completely oxidized rhodium sponge.

above $923 \mathrm{~K}$, up to 5.1 theoretical monolayers of atomic oxygen at $948 \mathrm{~K}$.

The peak maximum of each individual response of oxygen shifts to a larger time value than the peak maximum of the argon response (see Fig. 4), which points to reversible adsorption of oxygen at the catalyst surface. A fter a time interval of 2 s desorption of dioxygen is no longer observed.

Interaction of $M$ ethane with Reduced R hodium

The interaction of methane with the catalyst was investigated by introducing a single pulse of methane. In this case the catalyst was completely reduced prior to the experiment. Methane and hydrogen responses were monitored at the reactor outlet. No formation of carbon monoxide, carbon dioxide, ethane, and ethene was observed. The residence time of methane amounted to 0.2 sand that of hydrogen to $0.4 \mathrm{~s}$. The carbon balance was significantly negative, while the hydrogen balance was closed within $7 \%$ or less,

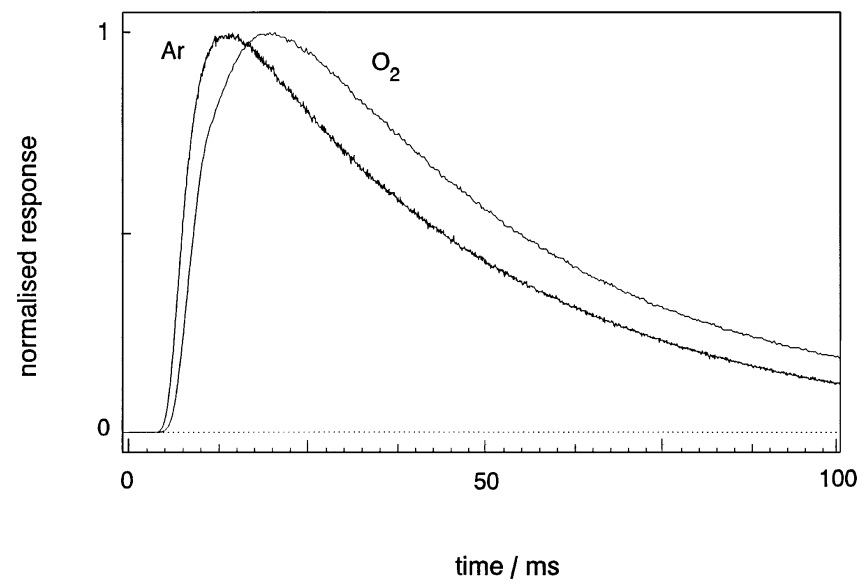

FIG . 4. Normalized responses of argon $(\times 5)$ and oxygen as a function of time. Pulse experiment of argon and oxygen at $1023 \mathrm{~K}$ over almost completely oxidized rhodium sponge. 
indicating the formation of carbon adatoms. The conversion of methane increased from $44 \%$ at $598 \mathrm{~K}$ to $81 \%$ at $748 \mathrm{~K}$. The apparent activation energy for methane decomposition amounted to $15 \mathrm{~kJ} \mathrm{~mol}^{-1}$.

\section{A Iternating Pulse Experiments over R hodium}

The role of adsorbed oxygen species was investigated with alternating pulse experiments of oxygen and methane and vice versa. A $n$ admitted methane to oxygen molar ratio of 0.5 was used to ensure complete reoxidation of the catalyst. No oxygen was detected quantitatively and the carbon as well as hydrogen balances were always closed. The oxygen balance is not closed at all time intervals applied and some oxygen is incorporated into the catalyst. However, this does not influence the experimental results since this amount is very small compared to the amount of $\mathrm{R}_{2} \mathrm{O}_{3}$ already present. Prior to the experiments the catalyst was treated with a continuous flow of methane and oxygen with a molar feed ratio of 0.5 until a steady state was reached. Product formation was only observed during the methane pulse.

First, an experiment starting with oxygen was carried out. Seven different time intervals between the oxygen and methane pulse were applied, varying from zero, i.e., simultaneous pulsing, up to $9 \mathrm{~s}$. Figure 5 shows the selectivities to $\mathrm{H}_{2}$ and $\mathrm{CO}$ as a function of the time interval between the oxygen and the methane pulse. The selectivity to $\mathrm{CO}$ increases from $7 \%$ when pulsing simultaneously to $33 \%$ at a time interval of $2 \mathrm{~s}$, while the corresponding $\mathrm{H}_{2}$ selectivity increases from 18 to $58 \%$. The selectivities to $\mathrm{CO}$ and $\mathrm{H}_{2}$ do not vary significantly when the time interval between the methane and oxygen pulse is further increased from $2 \mathrm{~s}$ up to $9 \mathrm{~s}$.

Next, an experiment starting with methane was performed, the time interval being varied between zero and

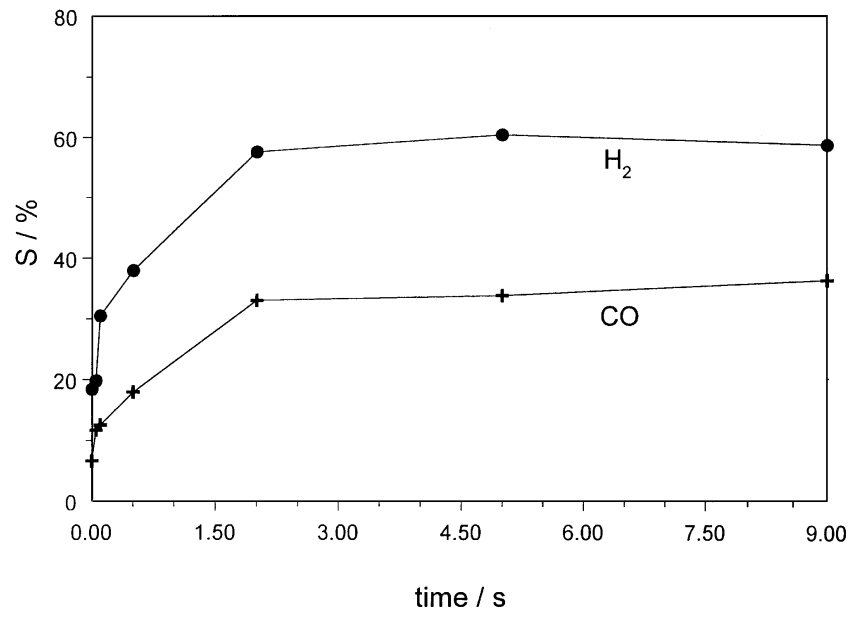

FIG. 5. Selectivities of $\mathrm{CO}$ and $\mathrm{H}_{2}$ as a function of the time interval between the oxygen and methane pulse. A Iternating pulse experiment starting with oxygen at $973 \mathrm{~K}$ over rhodium sponge ( $\left.2.1 \mathrm{wt} \% \mathrm{R}_{2} \mathrm{O}_{3}\right)$ and a methane to oxygen feed molar ratio of 0.5 .

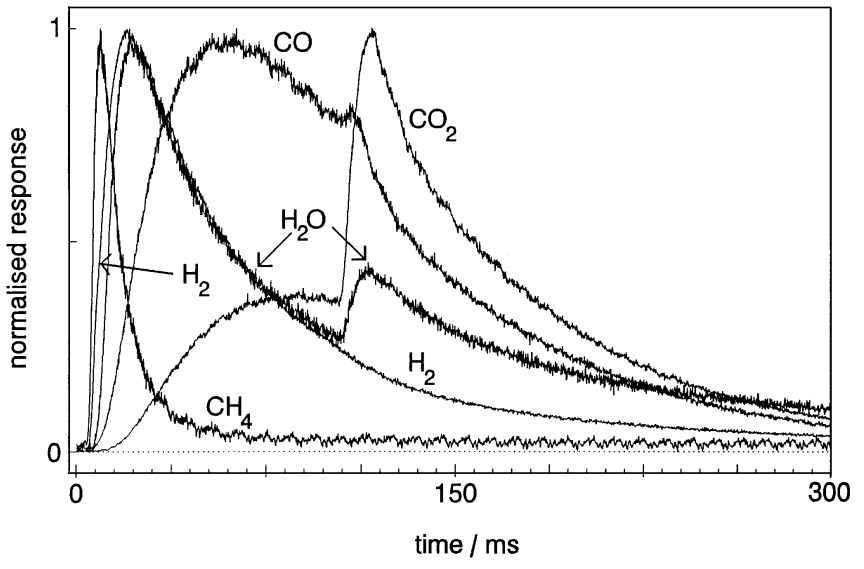

FIG. 6. Normalized responses of $\mathrm{CH}_{4}(\times 38), \mathrm{CO}(\times 2.4), \mathrm{CO}_{2}(\times 1.7)$, and $\mathrm{H}_{2}$ and $\mathrm{H}_{2} \mathrm{O}(\times 4.3)$ as a function of time. A Iternating pulse experiment starting with methane followed by oxygen at a time interval of $0.1 \mathrm{~s}$. $\mathrm{R}$ hodium sponge ( $2.1 \mathrm{wt} \% \mathrm{R}_{2} \mathrm{O}_{3}$ ), a methane to oxygen feed molar feed ratio of 0.5 and a temperature of $973 \mathrm{~K}$.

$1.0 \mathrm{~s}$. The selectivity to $\mathrm{CO}$ increases from $7 \%$ when simultaneous pulsing to $46 \%$ at a time interval of $0.5 \mathrm{~s}$, while the corresponding selectivity to $\mathrm{H}_{2}$ increases from 18 to $70 \%$. I ncreasing the time interval further to 1 shasno influence on the selectivities to $\mathrm{CO}$ and $\mathrm{H}_{2}$. From a time interval of $0.5 \mathrm{~s}$ onward the oxygen was introduced into the reactor when gaseous methane was no longer present in the catalyst bed. No formation of carbon-containing reaction products was observed during the interaction of oxygen with the catalyst. The normalized responses of $\mathrm{CO}, \mathrm{H}_{2}, \mathrm{CO}_{2}$, and $\mathrm{H}_{2} \mathrm{O}$ applying a time interval of $0.1 \mathrm{~s}$ between the methane and oxygen pulse are shown in Fig. 6 . The starting point and peak maximum of $\mathrm{CO}$ are observed prior to those of $\mathrm{CO}_{2}$. A similar conclusion can be drawn from the responses of $\mathrm{H}_{2}$ and $\mathrm{H}_{2} \mathrm{O}$. Furthermore, as soon as oxygen is introduced into the reactor and thus chemisorbed oxygen species are formed, the formation of $\mathrm{CO}_{2}$ abruptly increases, while that of $\mathrm{CO}$ decreases. Similar behavior of the $\mathrm{H}_{2}$ and $\mathrm{H}_{2} \mathrm{O}$ responses is observed, though the effects are less pronounced due to the fact that most gaseous hydrogen has al ready left the reactor at the moment dioxygen is introduced. A t smaller time intervals between the methane and oxygen pulse the decrease in the hydrogen response is much more pronounced.

\section{Simultaneous I nteraction of M ethane and O xygen \\ with R hodium during $P$ ulse $E$ xperiments}

The simultaneous interaction of methane and oxygen with the catalyst was investigated applying both unlabeled and labeled dioxygen. No oxygen was detected quantitatively and the carbon, hydrogen, and oxygen balances were always closed. The role of oxygen present at $\mathrm{R}_{2} \mathrm{O}_{3}$ versus adsorbed oxygen in the partial oxidation of methane was investigated by a multipulse experiment of $\mathrm{CH}_{4}$ and ${ }^{18} \mathrm{O}_{2}$ at a stoichiometric feed ratio. Prior to the experiment the 
catalyst was treated with a continuous flow of $\mathrm{CH}_{4}$ and ${ }^{16} \mathrm{O}_{2}$ at a stoichiometric feed ratio, which means that $\mathrm{R}_{2}{ }^{16} \mathrm{O}_{3}$ is present. $\mathrm{E}$ ight pulses of $\mathrm{CH}_{4}$ and ${ }^{18} \mathrm{O}_{2}$ were introduced into the reactor with a 5-s time interval between the pulses. Formation of $\mathrm{H}_{2}(\mathrm{~S}=95 \%), \mathrm{H}_{2}{ }^{16} \mathrm{O}(\mathrm{S}=2.6 \%), \mathrm{H}_{2}{ }^{18} \mathrm{O}(\mathrm{S}=$ $2.4 \%), \mathrm{C}^{16} \mathrm{O}_{2}(\mathrm{~S}=2.9 \%)$, and $\mathrm{C}^{16} \mathrm{O}^{18} \mathrm{O}(\mathrm{S}=1.1 \%)$ was already observed during the first pulse and the selectivities remained the same during the subsequent seven pulses of the multipulse experiment. The selectivities of $\mathrm{C}^{16} \mathrm{O}$ and $\mathrm{C}^{18} \mathrm{O}$ as a function of the pulse number are shown in Fig. 7 , which is a compilation of the results of two multipulse experiments. B etween the two experiments the state of the catalyst was restored by treatment with a continuous flow of $\mathrm{CH}_{4}$ and ${ }^{16} \mathrm{O}_{2}$ at a stoichiometric feed ratio until no further formation of labeled products was observed. During the first pulse no formation of $\mathrm{C}^{18} \mathrm{O}$ was observed, (see Fig. 7), and the selectivity increases up to $25 \%$ at the eighth pulse. The selectivity to $\mathrm{C}^{16} \mathrm{O}$ decreases from $96 \%$ to $71 \%$, which means that the cumulative selectivity to $\mathrm{CO}$ remains constant at a level of $96 \%$ during the multipulse experiment. D uring the first pulse $95 \%$ of the ${ }^{18} \mathrm{O}$ was incorporated into the catalyst, which decreases to $70 \%$ at the eighth pulse.

Simultaneous pulse experiments of $\mathrm{CH}_{4}$ and ${ }^{16} \mathrm{O}_{2}$ were carried out 923,973 , and $1023 \mathrm{~K}$ at feed molar ratios of 2 , 1 , and 0.5 . Prior to the experiments the catalyst was treated with a continuous flow of $\mathrm{CH}_{4}$ and $\mathrm{O}_{2}$ in the same molar as the experiment to follow. The selectivities to $\mathrm{CO}$ and $\mathrm{H}_{2}$ at $973 \mathrm{~K}$ increase from 7 and $18 \%$ at a ratio of 0.5 , to 34 and $64 \%$ at a ratio of 1 , and finally to 90 and $94 \%$ at a ratio of

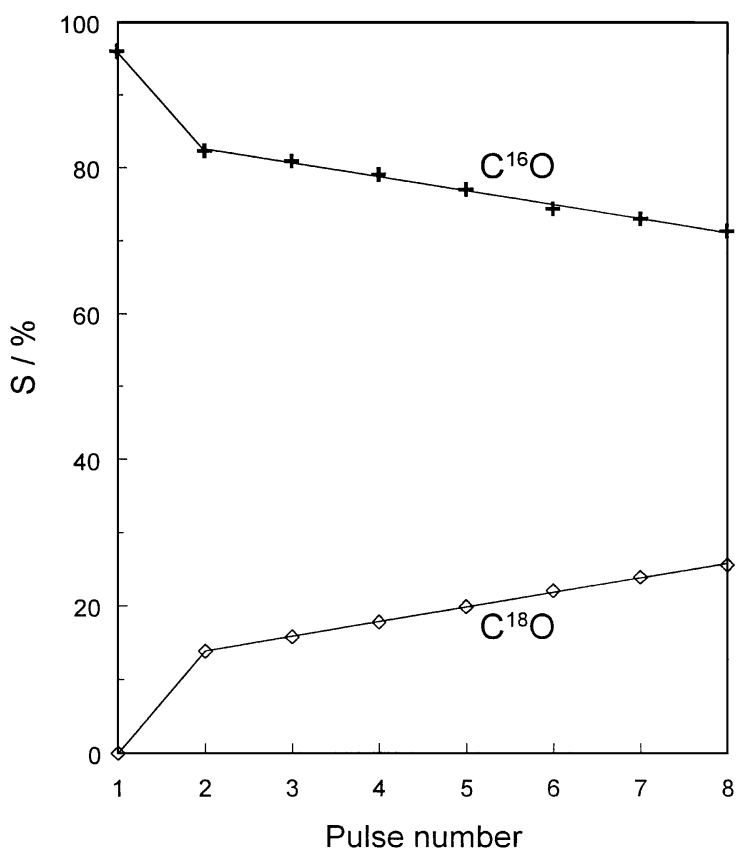

FIG . 7. Selectivities to $C^{16} O$ and $C^{18} O$ as a function of the pulse number. $\mathrm{M}$ ultipulse experiment of eight pulses of $\mathrm{CH}_{4} /{ }^{18} \mathrm{O}_{2}$ at a feed molar ratio of 2 at $973 \mathrm{~K}$ over rhodium sponge $\left(0.4 \mathrm{wt} \% \mathrm{R} \mathrm{h}_{2}{ }^{16} \mathrm{O}_{3}\right)$.

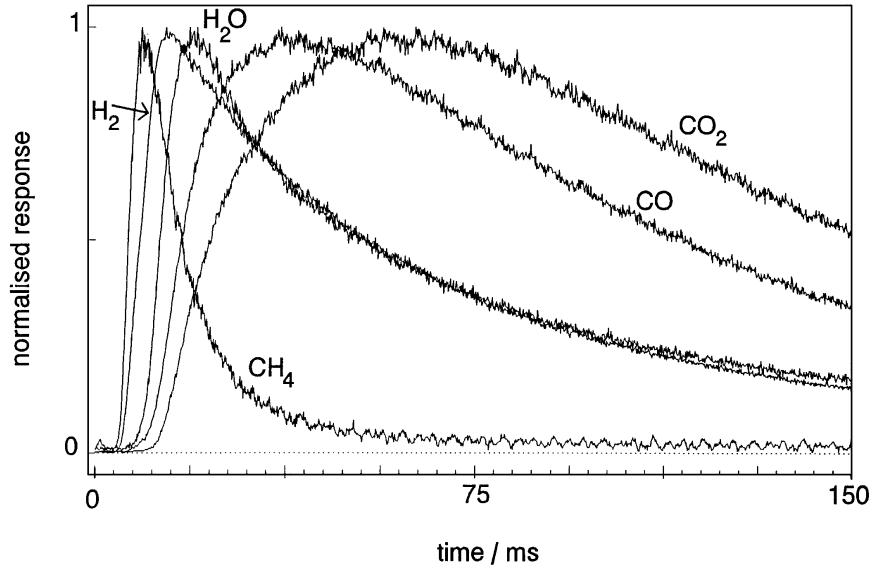

FIG . 8. Normalized responses of $\mathrm{CH}_{4}(\times 25), \mathrm{CO}(\times 2.9), \mathrm{CO}_{2}(\times 12)$, and $\mathrm{H}_{2}$ and $\mathrm{H}_{2} \mathrm{O}(\times 10)$ as a function of time. Simultaneous pulse experiments of $\mathrm{CH}_{4} / \mathrm{O}_{2}$ at a feed molar ratio of 2 over rhodium sponge ( $0.4 \mathrm{wt} \%$ $\mathrm{R}_{2} \mathrm{O}_{3}$ ) at $973 \mathrm{~K}$.

2. The selectivities to $\mathrm{CO}$ and $\mathrm{H}_{2}$ are hardly influenced by the reaction temperature in the range of 923 to $1023 \mathrm{~K}$.

The normalized responses of $\mathrm{CO}, \mathrm{CO}_{2}, \mathrm{H}_{2}$, and $\mathrm{H}_{2} \mathrm{O}$ from a simultaneous pulse experiment of $\mathrm{CH}_{4}$ and ${ }^{16} \mathrm{O}_{2}$ at a stoichiometric feed ratio at $973 \mathrm{~K}$ are shown in Fig. 8. The starting point and maximum of the $\mathrm{H}_{2}$ response are observed before those of the $\mathrm{H}_{2} \mathrm{O}$ response. F urthermore, the starting point and maximum of the $\mathrm{CO}$ response are observed before those of the $\mathrm{CO}_{2}$ response.

Simultaneous I nteraction of $M$ ethane and $O$ xygen with

R hodium during Continuous F low Experiments

Experiments with a continuous flow of methane and oxygen with feed molar ratios of 2,1 , and 0.5 were carried out to investigate the influence of reaction temperature and feed ratio on the conversion and product selectivities. In none of the experiments was dioxygen detected quantitatively nor were $\mathrm{C}_{2}$-products observed. The carbon, hydrogen, and oxygen balances were closed. The conversion of methane and selectivities of $\mathrm{CO}$ and $\mathrm{H}_{2}$ are shown in Figs. 9 and 10 for a $\mathrm{CH}_{4}$ to $\mathrm{O}_{2}$ feed molar ratio of 2 . Figure 9 shows that the methane conversion increases from $30 \%$ at $773 \mathrm{~K}$ to become nearly complete at $973 \mathrm{~K}$. The corresponding selectivities of $\mathrm{CO}$ and $\mathrm{H}_{2}$ increase from 76 and $29 \%$ to $100 \%$ (see Fig. 10). A t a feed molar feed ratio of 1, the conversion of methane increases from $44 \%$ at $773 \mathrm{~K}$ to $100 \%$ at $823 \mathrm{~K}$. The selectivity of $\mathrm{H}_{2}$ increases from $2 \%$ at $773 \mathrm{~K}$ to $77 \%$ at $823 \mathrm{~K}$ and then slightly decreases to $72 \%$ at $1023 \mathrm{~K}$, while the selectivity to $\mathrm{CO}$ increases from approximately zero up to $49 \%$ in the same temperature range. In the case of a $\mathrm{CH}_{4}$ to $\mathrm{O}_{2}$ feed molar ratio of 0.5 the conversion of methane is nearly complete and solely $\mathrm{CO}_{2}$ and $\mathrm{H}_{2} \mathrm{O}$ are produced in the temperature range of 773 to $1023 \mathrm{~K}$.

The amount of $\mathrm{R}_{2} \mathrm{O}_{3}$ present during the simultaneous interaction of methane and oxygen was investigated as a 


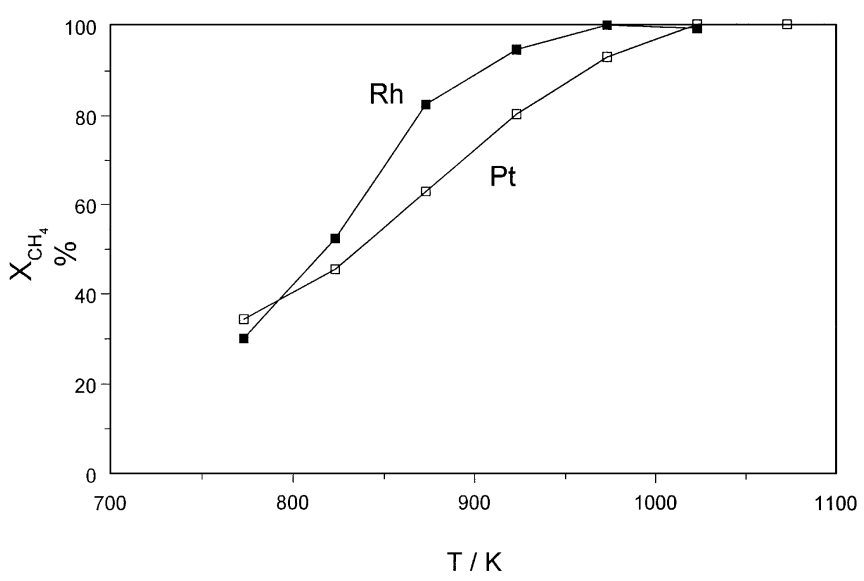

FIG. 9. Conversion of methane as a function of temperature for rhodium $\left(0.4\right.$ wt\% $\left.\mathrm{Rh}_{2} \mathrm{O}_{3}\right)$ and platinum sponge $\left(0.9\right.$ wt\% $\left.\mathrm{PtO}_{2}\right)$. Continuous flow experiment of $\mathrm{CH}_{4} / \mathrm{O}_{2}$ at a feed molar ratio of 2 . The oxygen conversion was complete in all experiments.

function of the methane to oxygen feed molar ratio at $973 \mathrm{~K}$. A s soon as the steady state was reached, the flow of reactants was switched off and the amount of $\mathrm{R}_{2} \mathrm{O}_{3}$ was determined by means of $\mathrm{H}_{2}$ multipulse reduction. The percentages of rhodium oxidized, assuming an oxide stoichiometry of $\mathrm{R}_{2} \mathrm{O}_{3}$, are shown in Table 2, for the three different $\mathrm{CH}_{4}$ to $\mathrm{O}_{2}$ feed molar ratios. The amount of $\mathrm{R}_{2} \mathrm{O}_{3}$ present at reaction conditions increasesfrom $0.4 \mathrm{wt} \%$ at a stoichiometric feed ratio to $2.1 \mathrm{wt} \%$ at a methane to oxygen feed molar ratio of 0.5 at a temperature of $973 \mathrm{~K}$. The first amounts to 10 theoretical monolayers of atomic oxygen.

Simultaneous I nteraction of $\mathrm{M}$ ethane and $\mathrm{O}$ xygen with Platinum during Continuous Flow Experiments

A s for rhodium, experiments with a continuous flow of methane and oxygen with feed molar ratios of 2,1 , and

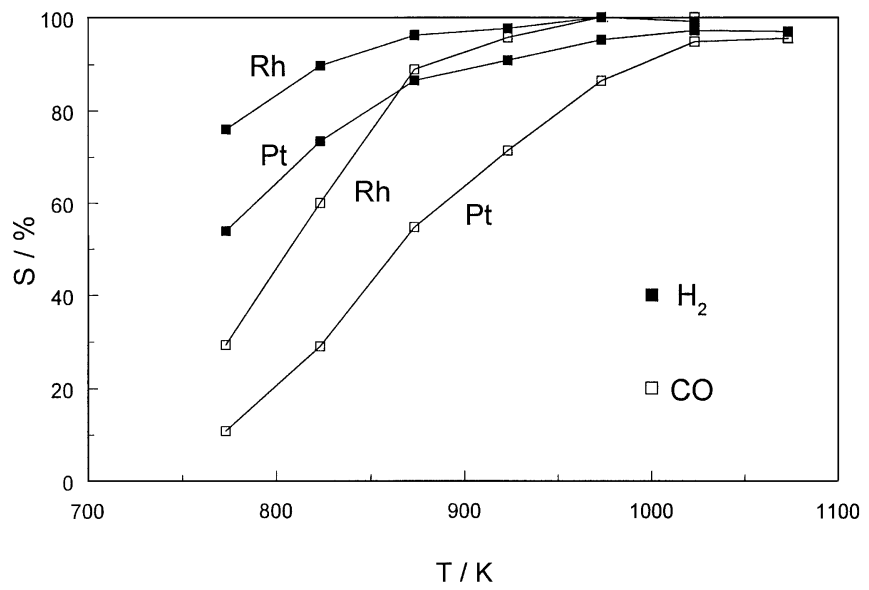

FIG. 10. Selectivity to $\mathrm{CO}$ and $\mathrm{H}_{2}$ as a function of temperature for rhodium $\left(0.4 \mathrm{wt} \% \mathrm{R} \mathrm{h}_{2} \mathrm{O}_{3}\right)$ and platinum sponge ( $\left.0.9 \mathrm{wt} \% \mathrm{PtO}_{2}\right)$. Continuous flow experiment of $\mathrm{CH}_{4} / \mathrm{O}_{2}$ at a feed molar ratio of 2 . The oxygen conversion was complete in all experiments.
TABLE 2

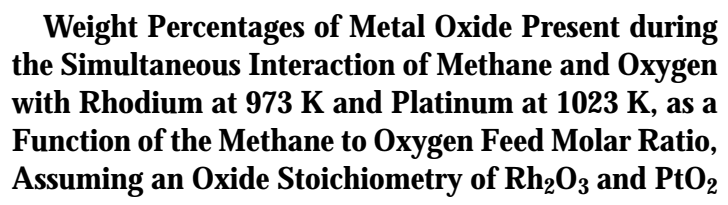

\begin{tabular}{ccc}
\hline $\mathrm{CH}_{4} / \mathrm{O}_{2}$ R atio & $\mathrm{Rh}_{2} \mathrm{O}_{3}(\mathrm{wt} \%)$ & $\mathrm{PtO}_{2}(\mathrm{wt} \%)$ \\
\hline 0.5 & 2.1 & 2.9 \\
1 & 0.6 & 1.5 \\
2 & 0.4 & 0.9 \\
\hline
\end{tabular}

0.5 were carried out. The total flow rate and the amount of surface platinum atoms are equal to that in the case of rhodium. Dioxygen was not detected quantitatively in any of the experiments nor were $\mathrm{C}_{2}$-products observed. The carbon, hydrogen, and oxygen balances were always closed.

The results at a stoichiometric feed ratio are compared to that of rhodium in Figs. 9 and 10. The conversion of methane (Fig. 9) is al ways higher for rhodium compared to platinum in the temperature range of $800 \mathrm{~K}$ up to $1000 \mathrm{~K}$. The selectivities of $\mathrm{H}_{2}$ and $\mathrm{CO}$ (Fig. 10) are also higher for rhodium compared to platinum. A t $773 \mathrm{~K}$ the difference in $\mathrm{H}_{2}$ selectivity amounts to $22 \%$, while that to $\mathrm{CO}$ amounts to $16 \%$. A t $923 \mathrm{~K}$ the difference in methane conversion between rhodium and platinum amounts to $15 \%$ and in the $\mathrm{CO}$ and $\mathrm{H}_{2}$ selectivity 25 and $7 \%$. A t a temperature of $1000 \mathrm{~K}$ the selectivities to $\mathrm{CO}$ and $\mathrm{H}_{2}$ are comparable.

A t a feed molar ratio of 1 the conversion of methane increases from $75 \%$ at $773 \mathrm{~K}$ to $100 \%$ at $973 \mathrm{~K}$. The selectivity to $\mathrm{CO}$ increases from 15 to $53 \%$ in the temperature range of 773 to $1023 \mathrm{~K}$, while the corresponding selectivity to $\mathrm{H}_{2}$ increases from 58 to $71 \%$. A t a feed molar ratio of 0.5 a complete conversion of methane to $\mathrm{CO}_{2}$ and $\mathrm{H}_{2} \mathrm{O}$ was observed in the temperature range of 773 to $1023 \mathrm{~K}$.

The amount of platinum oxide, assuming a stoichiometry of $\mathrm{PtO}_{2}$, was determined as a function of the feed molar ratio at a temperature of $1023 \mathrm{~K}$. The results are presented in Table 2. The amount of $\mathrm{PtO}_{2}$ present at reaction conditions increases with decreasing methane to oxygen molar ratio from $0.9 \mathrm{wt} \%$ at a stoichiometric feed ratio to $2.9 \mathrm{wt} \%$ at a feed molar ratio of 0.5 at a temperature of $1023 \mathrm{~K}$. The first amounts to 48 theoretical monolayers of atomic oxygen.

\section{DISCUSSION}

Interaction of Dioxygen and M ethane with Reduced R hodium

Exposure of the reduced rhodium catalyst to a continuous flow of oxygen at $1073 \mathrm{~K}$ leads to the almost complete oxidation of the latter of $\mathrm{R}_{2} \mathrm{O}_{3}$.

The incorporation of oxygen during the multipulse experiments (Fig. 3) is attributed to the decomposition of the $\mathrm{R}_{2} \mathrm{O}_{3}$ phase at a pressure of $10^{-5} \mathrm{~Pa}$ and temperatures 
in the range of 875 to $948 \mathrm{~K}$. Contrary to platinum, dissolved oxygen species are not present, since no constant value is reached in the amount of incorporated oxygen as a function of the time of maintaining the oxidized catalyst at $10^{-5} \mathrm{~Pa}$. M oreover, by interaction of dioxygen rhodium is almost completely oxidized, whereas platinum is oxidized only to an extent of $6 \mathrm{wt} \%$. The decomposition rate of $\mathrm{R}_{2} \mathrm{O}_{3}$ is relatively slow since at a temperature of $948 \mathrm{~K}$ only an amount of oxygen equivalent to five theoretical monolayers is removed from the catalyst after a period of $900 \mathrm{~s}$. The time scale of a typical TA P experiment amounts to $2 \mathrm{~s}$ and therefore the decomposition of $\mathrm{R}_{2} \mathrm{O}_{3}$ can be neglected during the simultaneous pulse experiments of methane and oxygen.

The shift of the peak maximum of the individual oxygen responses to a larger time value than that of the argon response (Fig. 4) is attributed to the reversible adsorption of oxygen at the catalyst surface. These species are assigned as dissociatively chemisorbed oxygen species, formed by the interaction of dioxygen with the catalyst surface. The time scale for desorption of the chemisorbed oxygen species amounts to $2 \mathrm{~s}$.

The interaction of methane with reduced rhodium results in the formation of carbon adatoms and gaseous hydrogen. The apparent activation energy for methane decomposition of $15 \mathrm{~kJ} \mathrm{~mol}^{-1}$ is in reasonable agreement with the value of $21 \mathrm{~kJ} \mathrm{~mol}^{-1}$ reported by B rass and E hrlich (42) for the dissociative chemisorption of methane on rhodium films.

\section{Steady State of R hodium at Temperatures and a $\mathrm{G}$ as}

Composition Typical for Catalytic

Partial Oxidation

Whereas the catalyst is almost completely oxidized to $\mathrm{R}_{2} \mathrm{O}_{3}$ in the presence of dioxygen alone, it is largely reduced during the simultaneous interaction of methane and oxygen at a stoichiometric feed ratio. The latter state corresponds to a steady state as indicated by the closed balances. O nly 0.4 wt\% $\mathrm{R} \mathrm{h}_{2} \mathrm{O}_{3}$ is present, equivalent to 10 theoretical monolayers of atomic oxygen. A t decreasing methane to oxygen feed molar ratio, the percentage of $\mathrm{R}_{2} \mathrm{O}_{3}$ present increases.

A physical picture of a rhodium surface consisting of a matrix of metallic rhodium and islands of an oxide phase seems to be in line with literature results. The existence of a mixed phase, consisting of metallic $\mathrm{Rh}$ and $\mathrm{Rh}_{2} \mathrm{O}_{3}$ is reported by Peuckert (25) and is stable up to $800-850 \mathrm{~K}$. The mixed phase may be represented as $\mathrm{R}_{2} \mathrm{O}_{3}$ clusters dispersed in a rhodium metal matrix. Salanov and Savchenko $(21,22)$ conclude that the formation of an island consisting of a surface oxide phase occurs at $500-700 \mathrm{~K}$ and thermal decomposition takes place at $750-900 \mathrm{~K}$ to yield dioxygen. Janssen et al. (43) studied the initial process of the oxidation of rhodium by field emission microscopy (FEM) and report formation of an oxide species on rhodium. This oxide species decomposes and oxygen desorbs between 800 and $1000 \mathrm{~K}$. The oxidative process is reported to be surfacestrcuture sensitive: the more open and rough the surface area, the more easy the oxidation.

\section{Interaction of M ethane with Chemisorbed}

Oxygen on R hodium

The leveling off of the increasing selectivities of $\mathrm{CO}$ and $\mathrm{H}_{2}$ from time intervals of 2 s between the pulsing of oxygen and methane onward (Fig. 5) indicates that chemisorbed oxygen is involved in the nonselective reaction paths of the partial oxidation of methane. Figure 6 shows that as soon as chemisorbed oxygen species are formed, the formation of $\mathrm{CO}_{2}$ from $\mathrm{CO}$ increases. In the case of $\mathrm{H}_{2}$ and $\mathrm{H}_{2} \mathrm{O}$ a similar behavior is observed. These results indicate that chemisorbed oxygen species are involved in the consecutive oxidation of $\mathrm{CO}$ to $\mathrm{CO}_{2}$ and $\mathrm{H}_{2}$ to $\mathrm{H}_{2} \mathrm{O}$.

The absence of any carbon-containing product formation during an alternating pulse experiment starting with methane for time intervals longer than $0.5 \mathrm{~s}$ indicates that reactive carbon species with a long lifetime are not present on the surface as long as oxygen species are present.

\section{P rimary Product Formation on Rhodium}

D uring the simultaneous interaction of methane and oxygen at a stoichiometric feed ratio (Fig. 8) the starting point and maximum of the $\mathrm{H}_{2}$ response is observed prior to those of the response of $\mathrm{H}_{2} \mathrm{O}$. Similarly, the starting point and maximum of the $\mathrm{CO}$ response are observed prior to those of $\mathrm{CO}_{2}$.

The order of appearance of $\mathrm{H}_{2}$ and $\mathrm{CO}$ as well as $\mathrm{H}_{2} \mathrm{O}$ and $\mathrm{CO}_{2}$ as shown in Fig. 8 indicates that the former products are formed prior to the latter. O ne could argue that the order of appearance is determined by differences in $K$ nudsen diffusion and adsorption/desorption coefficients. The order of appearance obtained by simulating the above phenomena for $\mathrm{CO}, \mathrm{H}_{2}, \mathrm{H}_{2} \mathrm{O}$, and $\mathrm{CO}_{2}$ (see Fig. 1) corresponds to the order of appearance expected for a pulse experiment with $\mathrm{CH}_{4}$ and $\mathrm{O}_{2}$ with all four of the reaction products formed in a parallel way. The starting point and maximum of $\mathrm{CO}_{2}$ is observed prior to that of $\mathrm{CO}$. It follows from Fig. 8 that on the contrary during the simultaneous interaction of methane and oxygen the starting point and peak maximum of the $C O$ response is observed prior to that of $\mathrm{CO}_{2}$. I is concluded that $\mathrm{CO}$ is a primary reaction product. A similar conclusion is drawn for $\mathrm{H}_{2}$ and $\mathrm{H}_{2} \mathrm{O}$, with hydrogen being the primary reaction product.

In the simulations the rate coefficients for adsorption and desorption of $\mathrm{H}_{2}, \mathrm{H}_{2} \mathrm{O}$, and $\mathrm{CO}$ of $\mathrm{Hickman}$ and Schmidt (18) were used, which are valid for metal surfaces. In the present study a rhodium surface consisting of a matrix of metallic rhodium and islands of an oxide is proposed during the steady state at temperatures and gas composition typical for catalytic partial oxidation. H owever, it is assumed 
that the surface is reduced in such a degree to allow the use of the rate constants of $\mathrm{H}$ ickman and Schmidt (18). During the simultaneous interaction of methane and oxygen at a stoichiometric feed ratio and closed balances, the direct formation of synthesis gas occurs. $\mathrm{CO}$ and $\mathrm{H}_{2}$ are oxidized to $\mathrm{CO}_{2}$ and $\mathrm{H}_{2} \mathrm{O}$ via consecutive reaction paths.

\section{R eaction M echanism on R hodium}

The multipulse experiments of $\mathrm{CH}_{4}$ and ${ }^{18} \mathrm{O}_{2}$ provide detailed information on the role of oxygen present as $\mathrm{R}_{2} \mathrm{O}_{3}$ versus chemisorbed oxygen in the partial oxidation of methane. $D$ uring the first pulse, no formation of $C^{18} \mathrm{O}$ was observed while $\mathrm{C}^{16} \mathrm{O}$ is being formed (Fig. 7), which means that formation of $\mathrm{CO}$ only proceeds via oxygen present as $\mathrm{R}_{2}{ }^{16} \mathrm{O}_{3}$. The formation of $\mathrm{C}^{16} \mathrm{O}^{18} \mathrm{O}$ and $\mathrm{C}^{16} \mathrm{O}_{2}$ during the first pulse indicates that both chemisorbed oxygen and $\mathrm{R}_{2}{ }^{16} \mathrm{O}_{3}$ are involved in the consecutive oxidation of $\mathrm{C}^{16} \mathrm{O}$. Chemisorbed oxygen and $\mathrm{R}_{2}{ }^{16} \mathrm{O}_{3}$ are both also involved in the consecutive oxidation of $\mathrm{H}_{2}$, since formation of $\mathrm{H}_{2}{ }^{16} \mathrm{O}$ as well as $\mathrm{H}_{2}{ }^{18} \mathrm{O}$ is observed during the first pulse. The role of chemisorbed oxygen in the consecutive oxidation of $\mathrm{CO}$ and $\mathrm{H}_{2}$ wasal ready concluded from the alternating pulse experiments and is in line with the labeled oxygen experiment.

O nly $5 \%$ of the total amount of ${ }^{18} \mathrm{O}$ pulsed in the first pulse is incorporated into the reaction products. The remainder of the ${ }^{18} \mathrm{O}$ is incorporated into the catalyst, which results in the formation of labeled rhodium oxide. A s a result, the selectivity to $C^{16} O$ decreases and that to $C^{18} O$ increases at increasing pulse number (see Fig. 7).

Based on the experimental findings, the following reaction mechanism is proposed for the partial oxidation of methane over rhodium. M ethane dissociates to carbon and hydrogen adatoms on reduced rhodium. It is assumed that the abstraction of $\mathrm{H}$ adatoms from $\mathrm{CH}_{\mathrm{x}}$ species by $\mathrm{O}$ adatoms does not occur to a significant extent. This reaction would lead to the formation of $\mathrm{OH}$ species and finally to $\mathrm{H}_{2} \mathrm{O}$ formation. However, the high selectivities to $\mathrm{H}_{2}$ indicate that this is not a dominant reaction step. O h et al. (44) proposed a mechanism for methane oxidation over alumina-supported noble metal catalysts in which $\mathrm{O}$ adatoms react with a $\mathrm{CH}_{\mathrm{x}}$ species to form formaldehyde, which decomposes into $\mathrm{CO}$ and two $\mathrm{H}$ adatoms. The methane to oxygen feed ratio was varied between 0.2 and 1 , and they report that the metal surface is predominantly covered with oxygen. This mechanism could account for primary formation of $\mathrm{CO}$ and $\mathrm{H}_{2}$. However, no formation of formaldehyde was observed in the present study and the methane to oxygen feed ratio amounts to 2 , resulting in a much lower oxygen coverage during the experiments.

The direct formation of $\mathrm{CO}$ from methane is believed to occur via a reaction between carbon adatoms and oxygen present as rhodium oxide. $\mathrm{H}$ ydrogen is formed as primary reaction product as well, via the associative desorption of two hydrogen adatoms from reduced rhodium. The con- secutive oxidation of $\mathrm{CO}$ and $\mathrm{H}_{2}$ occurs both via oxygen present as rhodium oxide and via chemisorbed oxygen.

Buyevskaya et al. (7) studied the partial oxidation of methane over $1 \mathrm{wt} \% \mathrm{Rh} / \gamma-\mathrm{Al}_{2} \mathrm{O}_{3}$. It was concluded that $\mathrm{CO}$ is a secondary product, formed by a surface reaction between carbon deposits and $\mathrm{CO}_{2}$, which are the primary products. H owever, their response analysis is complicated due to the high specific surface area of their catalyst, $91 \mathrm{~m}^{2} \mathrm{~g}^{-1}$ BET, which will influence the shape of the reponses due to diffusion in the pores of the catalyst. In situ DRIFTS studies performed on the same catalyts (8) led the authors to the conclusion that $\mathrm{OH}$ surface groups on the support are involved in the $\mathrm{CH}_{x}$ conversion to $\mathrm{CO}$ via a reforming reaction. A pparently, different results are obtained from experiments performed on a supported rhodium catalyst compared to the rhodium sponge of the present study. It is suggested that the $\gamma-\mathrm{A} \mathrm{I}_{2} \mathrm{O}_{3}$ support is not inert at reaction conditions, but can especially catalyze the total oxidation reactions.

The observations of the present study are consistent with the following mechanism for the formation of synthesis gas over rhodium:

\begin{tabular}{ll}
$\mathrm{CH}_{4}+5 * \rightarrow \mathrm{C} *+4 \mathrm{H} *$ & $\sigma$ \\
$\mathrm{C} *+\mathrm{Rh}_{x} \mathrm{O} \rightarrow \mathrm{Rh}_{x}^{0}+\mathrm{CO}+*$ & 2 \\
$\mathrm{O}_{2}+2 \mathrm{Rh}_{x}^{0} \rightarrow 2 \mathrm{Rh}_{x} \mathrm{O}$ & 1 \\
$2 \mathrm{H} * \rightarrow \mathrm{H}_{2}+2 *$ & 4 \\
\hline $2 \mathrm{CH}_{4}+\mathrm{O}_{2} \rightarrow 2 \mathrm{CO}+4 \mathrm{H}_{2} ;$ &
\end{tabular}

here $\sigma$ is the stoichiometric number.

The dissociation of methane, (Reaction 1 ) and the formation of $\mathrm{H}_{2}$, (Reaction 4) are believed to occur on reduced rhodium sites. The formation of $\mathrm{CO}$ proceeds via a redox cycle postulated by $M$ ars and van K revelen (45) for selective oxidation reactions. The oxidation of the carbon adatoms to $\mathrm{CO}$ ( $\mathrm{R}$ eaction 2 ) is accompanied by the reduction of rhodium oxide, which is reoxidized by incorporation of dioxygen into the catalyst ( $R$ eaction 3 ).

\section{Comparison between R hodium and $\mathrm{P}$ latinum}

The partial oxidation of methane to synthesis gas over platinum has been reported upon previously (32) and is summarized below. On reduced platinum the decomposition of methane results in the formation of carbon and hydrogen adatoms. In the presence of dioxygen only, oxygen is present in three different forms: platinum oxide, dissolved oxygen, and chemisorbed oxygen species. $\mathrm{CO}$ and $\mathrm{H}_{2}$ are produced directly from methane via oxygen present as platinum oxide. A ctivation of methane involving dissolved oxygen provides a parallel route to $\mathrm{CO}_{2}$ and $\mathrm{H}_{2} \mathrm{O}$. B oth platinum oxide and chemisorbed oxygen species are involved in the consecutive oxidation of $\mathrm{CO}$ and $\mathrm{H}_{2}$. In the presence 
of both methane and dioxygen at a stoichiometric feed ratio, dissolved oxygen species are not present and hence the dominant pathways are the direct formation of $\mathrm{CO}$ and $\mathrm{H}_{2}$, followed by their consecutive oxidation. A M ars-van $K$ revelen redox cycle was postulated for the partial oxidation of methane over platinum.

The results of the continuous flow experiments of $\mathrm{CH}_{4}$ and $\mathrm{O}_{2}$ at a stoichiometric feed ratio (see Figs. 9 and 10) show that rhodium is a more active and selective catalyst than platinum at a comparable temperature. In the investigated temperature range the difference in the selectivity to $\mathrm{CO}$ is more pronounced than the difference in selectivity to $\mathrm{H}_{2}$.

$\mathrm{H}$ ickman and Schmidt $(15,16)$ also observed a higher methane conversion over rhodium compared to platinum. Lapsewicz and Jiang (19) reported that methane activation is the rate-limiting step in the partial oxidation of methane. The difference in methane conversion can then be explained by the observed difference in apparent activation energy for methane activation on platinum, $52 \mathrm{~kJ} \mathrm{~mol}^{-1}$ (32), and rhodium, $15 \mathrm{~kJ} \mathrm{~mol}^{-1}$.

Lapsewicz and Jiang (19) ascribe the observed differences in $\mathrm{CO}$ selectivity to the differences in ratios of surface species, such asoxygen, carbon, and hydrogen adatoms. Since the chemisorption of oxygen is not activated, the ability of the catalyst to activate methane determines the ratios of surface species. A t increasing carbon to oxygen adatom ratio, the $\mathrm{CO}$ formation will be favored compared to the formation of $\mathrm{CO}_{2}$ and a high hydrogen to oxygen adatom ratio is beneficial for the hydrogen selectivity. H ence, the differences in the selectivity to $\mathrm{CO}$ as well as $\mathrm{H}_{2}$ observed in the present study can also be explained from the viewpoint that rhodium has a much lower activation energy than platinum for methane activation.

Contrary to the results of the present study, $\mathrm{H}$ ickman and Schmidt $(15,16)$ observed comparable selectivities to CO on $\mathrm{Pt}$ and $\mathrm{R} \mathrm{h}$ applying an autothermally operated reactor. The optimal selectivities are $S_{\mathrm{H}_{2}}=43 \%$ and $\mathrm{S}_{\mathrm{CO}}=89 \%$ for the platinum catalyst compared to $S_{\mathrm{H}_{2}}=73 \%$ and $\mathrm{S}_{\mathrm{CO}}=$ $90 \%$ for the rhodium catalyst. The difference in the $\mathrm{H}_{2}$ selectivity was explained by the higher activation energy for $\mathrm{OH}$ formation on $\mathrm{R} \mathrm{h}, 84 \mathrm{~kJ} \mathrm{~mol}^{-1}$, compared to platinum, $11 \mathrm{~kJ} \mathrm{~mol}{ }^{-1}$. Therefore, on rhodium $\mathrm{H}$ adatoms are more likely to combine and desorb as $\mathrm{H}_{2}$ than on $\mathrm{Pt}$, which allows a faster formation of $\mathrm{OH}$ species. This reasoning may also provide an explanation for the higher $\mathrm{H}_{2}$ selectivity of rhodium observed in the present study, in addition to the difference in the activation energy of methane activation. The discrepancy concerning the $\mathrm{CO}$ selectivity can be explained by the difference in mechanism. The balance between the rate of the oxidation and reduction steps determines the amount of metal oxide present at steady state. The lower amount of rhodium oxide present at steady state compared to platinum oxide at a stoichiometric feed ra- tio may explain the higher $\mathrm{CO}$ selectivity on rhodium since this could also correspond to a lower rate of the consecutive oxidation reaction of $\mathrm{CO}$.

$\mathrm{By}$ interaction with dioxygen, rhodium is almost completely oxidized to $\mathrm{R}_{2} \mathrm{O}_{3}$ at $1073 \mathrm{~K}$ and the formation of this oxide phase was confirmed by ex situ XRD and XPS measurements. For platinum a maximum amount of oxide equivalent to $6 \mathrm{wt} \% \mathrm{PtO}_{2}$ was formed at $1023 \mathrm{~K}$. H owever, the presence of a $\mathrm{PtO}_{2}$ phase could not be confirmed by an ex situ XRD analysis. D issolved oxygen species were not observed in the case of rhodium during the interaction with dioxygen, probably due to the almost complete oxidation of rhodium to $\mathrm{R}_{2} \mathrm{O}_{3}$.

D uring the simultaneous interaction of methane and oxygen the percentage of metal oxidized is larger for platinum than for rhodium (see Table 2). The difference is most pronounced at a stoichiometric feed ratio. In the steady state the amount of metal oxide results from the rate of metal oxidation by oxygen and the rate of oxide reduction by carbon adatoms. Hence, the differences between platinum and rhodium as shown in Table 2 may be explained by the lower activation energy for methane decomposition on rhodium, resulting in a higher concentration of carbon adatoms and thus a higher rate of oxide reduction.

\section{CONCLUSIONS}

D uring the interaction of dioxygen with rhodium sponge, the catalyst is almost completely oxidized to $\mathrm{R}_{2} \mathrm{O}_{3}$. In addition to rhodium oxide, oxygen is also present in the form of chemisorbed oxygen species. During the simultaneous interaction of methane and dioxygen at a stoichiometric feed ratio and a temperature of $973 \mathrm{~K}$ the catalyst is mainly in the metallic rhodium phase.

The decomposition of methane on reduced rhodium results in the formation of carbon and hydrogen adatoms. Synthesis gas is a primary product. H ydrogen is formed via the associative desorption of two hydrogen adatoms from reduced rhodium and the reaction between carbon adatoms and oxygen present as rhodium oxide results in the formation of carbon monoxide. The consecutive oxidation of $\mathrm{CO}$ and $\mathrm{H}_{2}$ proceeds via both chemisorbed oxygen and oxygen present as rhodium oxide. A Mars-van $\mathrm{K}$ revelen mechanism is postulated for the partial oxidation of methane over rhodium: methane reduces the rhodium oxide, which is reoxidized by dioxygen.

When compared to platinum, rhodium shows a higher methane conversion at a comparable temperature and also a higher selectivity to both $\mathrm{CO}$ and $\mathrm{H}_{2}$. A II differences are caused by the activation energy for methane decomposition which is higher on platinum than on rhodium. A n additional explanation for the observed difference in the $\mathrm{H}_{2}$ selectivity could be the higher activation energy for $\mathrm{OH}$ formation on rhodium compared to platinum. 


\section{APPENDIX: NOMENCLATURE}

Roman Symbols

$a_{\mathrm{v}} \quad$ External catalyst surface area per unit catalyst volume $\left(\mathrm{m}_{\mathrm{c}}^{2} \mathrm{~m}_{\mathrm{c}}^{-3}\right)$

$A_{\mathrm{s}} \quad$ Cross sectional area of the reactor $\left(\mathrm{m}_{\mathrm{r}}^{2}\right)$

$C \quad$ Concentration $\left(\mathrm{mol} \mathrm{m} \mathrm{g}^{-3}\right)$

$d_{\mathrm{i}} \quad$ D iameter of interstitial voids $(\mathrm{m})$

$d_{\mathrm{p}} \quad$ Particle diameter $(\mathrm{m})$

$D_{\mathrm{e}}^{\kappa} \quad$ Effective K nudsen diffusion coefficient $\left(\mathrm{m}_{\mathrm{g}}^{3} \mathrm{~m}_{\mathrm{r}}^{-1} \mathrm{~s}^{-1}\right)$

$k \quad$ R eaction rate coefficient (reaction dependent)

$l_{\mathrm{b}} \quad$ B ed length $\left(\mathrm{m}_{\mathrm{r}}\right)$

$L_{\mathrm{t}} \quad$ M aximal molar concentration per square meter catalyst surface $\left(\mathrm{mol} \mathrm{m}_{\mathrm{c}}^{-2}\right)$

$M \quad$ Molecular mass $\left(\mathrm{kg} \mathrm{mol}^{-1}\right)$

$n \quad$ Total amount of moles (mol)

$N_{\mathrm{p}} \quad$ A mount of a component in inlet pulse (mol)

$R \quad$ G eneral gas constant $\left(\mathrm{mol}^{-1} \mathrm{~K}^{-1}\right)$

$S \quad$ Selectivity $\left(\mathrm{mol} \mathrm{mol}^{-1}\right)$

$t \quad$ Time (s)

$T$ Temperature (K)

$x \quad$ A xial coordinate in reactor $(\mathrm{m})$

$X \quad$ Conversion $\left(\mathrm{mol} \mathrm{mol}^{-1}\right)$

G reek Symbols

$\varepsilon_{b} \quad$ Bed porosity $\left(\mathrm{m}_{\mathrm{g}}^{3} \mathrm{~m}_{\mathrm{r}}^{-3}\right)$

$\tau_{\mathrm{b}} \quad$ Bed tortuosity $\left(\mathrm{m}_{\mathrm{g}}^{2} \mathrm{~m}_{\mathrm{r}}^{-2}\right)$

$\theta \quad$ Fractional coverage on the catalyst surface

$\epsilon \quad$ M ass balance $\left(\mathrm{mol} \mathrm{mol}^{-1}\right.$ )

$\sigma \quad$ Stoichiometric number

$\tau \quad$ Time scale (s)

\section{Subscripts}

A With respect to $A$

ads Adsorption

b Bed; interstitial voids

des Desorption

diff Knudsen diffusion

* Vacant sites

\section{ACK NOWLEDGMENT}

The financial support provided by the Commision of the European U nion in the framework of the JOU LE programme, subprogramme Energy from Fossil Sources, H ydrocarbons, N o. J O U 2-CT 92-0073, is gratefully acknowledged.

\section{REFERENCES}

1. Prettre, M., Eichner, Ch., and Perrin, M ., Trans. Faraday Soc. 43, 335 (1946).

2. Dissanayake, D., R osynek, M . P., K haras, K. C. C., and L unsford, J. H ., J. Catal. 132, 117 (1991).
3. A shcroft, A. T., Cheetham, A . K ., Foord, J. S., G reen, M . L. H ., G rey, C. P., M urrell, A . J., and Vernon, P. D. F., N ature 344, 319 (1990).

4. Vernon, P. D. F., G reen, M . L. H., Cheetham, A. K., and A shcroft, A . T., Catal. L ett. 6, 181 (1990).

5. Vernon, P. D. F., G reen, M. L. H., Cheetham, A. K., and A shcroft, A . T., Catal. Today 13, 417 (1992).

6. Vermeiren, W. J. M., B lomsma, E., and Jacobs, P. A ., Catal. Today 13, 427 (1992).

7. Buyevskaya, O. V., Wolf, D., and Baerns, M., Catal. L ett. 29, 249 (1994).

8. Walter, K., Buyevskaya, O. V., Wolf, D., and B aerns, M., Cat. L ett. 29, 261 (1994).

9. Choudhary, V. R., R ajput, A . M ., and Prabhakar, B., Catal. L ett. 15, 363 (1992).

10. Choudhary, V. R ., R ajput, A . M ., and Prabhakar, B., J. Catal. 139, 326 (1993).

11. Choudhary, V. R ., R ajput, A. M ., and R ane, V. H ., J. Phys. Chem. 96, 8686 (1992).

12. Choudhary, V. R., R ajput, A . M ., and R ane, V. H ., C atal. L ett. 16, 269 (1992).

13. Choudhary, V. R ., Sansare, S. D., and M amman, A . S., A ppl. Catal. 90, L 1 (1992).

14. D issanayake, D., R osynek, M. P., and L unsford, J. H ., J. Phys. Chem. 97, 3644 (1993).

15. H ickman, D. A ., and Schmidt, L. D., Science 259, 343 (1993).

16. H ickman, D. A ., H aupfear, E . A ., and Schmidt, L. D., C atal. L ett. 17, 223 (1993).

17. H ickman, D. A ., and Schmidt, L. D., J. Catal. 138, 267 (1992).

18. H ickman, D. A ., and Schmidt, L. D., A IChE J. 39, 1164 (1993).

19. Lapszewicz, J. A ., and J iang, X.-Z, Prepr. A m. Chem. Soc. D iv. Pet. Chem. 37, 252 (1992).

20. M atsumura, Y., and M offat, J. B., C atal. L ett. 24, 59 (1994).

21. Salanov, A. N., and Savchenko, V. I., Surf. Sci. 296, 393 (1993).

22. Salanov, A. N., and Savchenko, V. I., K inet. Catal. 34, 478 (1993).

23. Salanov, A. N., and Savchenko, V. I., R eact. Catal. L ett. 49, 29 (1993).

24. Salanov, A. N., and Savchenko, V. I., K inet. Catal. 35, 722 (1994).

25. Peuckert, M., Surf. Sci. 141, 500 (1984).

26. Wang, T., and Schmidt, L. D., J. Catal. 71, 411 (1981).

27. Carol, L. A ., and M ann, G. S., O xid. M et. 34, 1 (1990).

28. Beck, D. D., Capehart. T. W., Wong, C., and Belton, D. N., J. Catal. 144, 311 (1993).

29. Kellog, G. L., P hys. Rev. L ett. 54, 1, 82 (1985).

30. K ellog, G. L., Surf. Sci. 171, 359 (1986).

31. O h, S. H., and Carpenter, J. E., J. Catal. 80, 472 (1983).

32. M allens, E. P. J., H oebink, J. H. B. J., and M arin, G. B., C atal. L ett. 33, 291 (1995).

33. G leaves, J. T., E bner, J. R ., and Kuechler, T. C., Catal. Rev.-Sci. Eng. 30, 49 (1988).

34. H uinink, J.P., Ph.D. Thesis, E indhoven U niversity of Technology, 1995.

35. H uizenga, D. G., and Smith, D. M., A IChE J. 32, 1 (1986).

36. Schäfer, H ., Tebben, A ., and G erhardt, W., Z . A norg. A llg. Chem. 321, 41 (1963).

37. A lcock, C. B., and H ooper, G. W., Proc. Roy. Soc. A 254, 551 (1960).

38. Barin, I., "Thermochemical Data of Pure Substances." VCH, Weinheim, 1993.

39. Heuer, A. H., and L ou, V. L. K., J. A m. Ceram. Soc. 73, 2785 (1990).

40. Lou, V. L. K., M itchell, T. E., and Heuer, A. H., J. A m. Ceram. Soc. 68, 49 (1985).

41. B arin, I., and K nacke, O., "Thermochemical Properties of Inorganic Substances." Springer-Verlag, B erlin, 1973.

42. B rass, S. G., and E hrlich, G., J. Chem. Phys. 87, 4285 (1987).

43. Janssen, N. M. H., van Tol, M. F. H., and Nieuwenhuys, B. E., A ppl. Surf. Sci. 74, 1 (1994).

44. O h. S. H., M itchell. P. J., and Siewert, R. M., J. Catal. 132, 287 (1991).

45. M ars, P., and van K revelen, D. W., Chem. Eng. Sci. 3, 41 (1954). 